\title{
cGMP-dependent protein kinase-2 regulates bone mass and prevents diabetic bone loss
}

\author{
Ghania Ramdani', Nadine Schall1,2, Hema Kalyanaraman', Nisreen Wahwah1, Sahar Moheize', Jenna J Lee², \\ Robert L Sah ${ }^{3}$, Alexander Pfeifer ${ }^{2}$, Darren E Casteel' ${ }^{1}$ and Renate B Pilz ${ }^{1}$
}

1Department of Medicine, University of California, San Diego, La Jolla, California, USA

2The Institute for Pharmacology and Toxicology, University of Bonn, Bonn, Germany

3Department of Bioengineering, University of California, San Diego, La Jolla, California, USA

Correspondence should be addressed to R B Pilz: rpilz@ucsd.edu

\section{Abstract}

NO/cGMP signaling is important for bone remodeling in response to mechanical and hormonal stimuli, but the downstream mediator(s) regulating skeletal homeostasis are incompletely defined. We generated transgenic mice expressing a partly-activated, mutant cGMP-dependent protein kinase type 2 (PKG2 ${ }^{\mathrm{R} 242 \mathrm{Q}}$ ) under control of the osteoblast-specific Col1a1 promoter to characterize the role of PKG2 in post-natal bone formation. Primary osteoblasts from these mice showed a two- to three-fold increase in basal and total PKG2 activity; they proliferated faster and were resistant to apoptosis compared to cells from WT mice. Male Col1a1-Prkg2R242Q transgenic mice had increased osteoblast numbers, bone formation rates and $\mathrm{Wnt} / \beta$-catenin-related gene expression in bone and a higher trabecular bone mass compared to their WT littermates. Streptozotocin-induced type 1 diabetes suppressed bone formation and caused rapid bone loss in WT mice, but male transgenic mice were protected from these effects. Surprisingly, we found no significant difference in bone micro-architecture or Wnt/ $\beta$-catenin-related gene expression between female WT and transgenic mice; female mice of both genotypes showed higher systemic and osteoblastic NO/cGMP generation compared to their male counterparts, and a higher level of endogenous PKG2 activity may be responsible for masking effects of the PKG2 ${ }^{R 242 Q}$ transgene in females. Our data support sexual dimorphism in Wnt/ $\beta$-catenin signaling and PKG2 regulation of this crucial pathway in bone homeostasis. This work establishes PKG2 as a key regulator of osteoblast proliferation and post-natal bone formation.

\author{
Key Words \\ - cGMP-dependent protein \\ kinase \\ - osteoblasts \\ - bone formation \\ - diabetic osteoporosis \\ - Wnt pathway \\ - sexual dimorphism
}

Journal of Endocrinology (2018) 238, 203-219

\section{Introduction}

Cyclic GMP is produced by two types of guanylyl cyclases (GCs): receptor GCs activated by peptide ligands such as C-type natriuretic peptide (CNP) and soluble GCs activated by nitric oxide (NO) (Hofmann et al. 2009, Hannema et al. 2013, Kuhn 2016). cGMP regulates ion channels, phosphodiesterases and two types of cGMPdependent protein kinases (PKG1 and 2), encoded by two homologous genes (Prkg1 and 2) (Hofmann et al. 2009). PKG1 is widely expressed with high levels found in the vasculature, whereas PKG2 expression is limited to specific cell types in bone, intestine, brain and kidney (Vaandrager et al. 2005). PKG1 and 2 are both found in osteoblasts and chondroblasts (Pfeifer et al. 1996, Rangaswami et al. 2009). 
The CNP/GC-B/PKG2 pathway regulates endochondral ossification, responsible for fetal skeletal development and post-natal longitudinal bone growth. Loss-of-function mutations or genetic ablation of CNP, GC-B or PKG2 cause dwarfism in humans and rodents, while increased CNP expression or a gain-of-function mutation in GC-B cause long bone overgrowth (Pfeifer et al. 1996, Chusho et al. 2001, Bartels et al. 2004, Bocciardi et al. 2007, Bonnet et al . 2010, Miura et al. 2012, Hannema et al. 2013).

The NO/soluble GC pathway regulates adult skeletal homeostasis: NO is required for the anabolic response of bone to mechanical stimulation and regulates bone remodeling downstream of estrogens and thyroid hormone (Watanuki et al. 2002, Rangaswami et al. 2010, Kalyanaraman et al. 2014, 2017, 2018a). Some strains of NOS3-deficient mice have reduced bone mass due to defects in osteoblast number and maturation, whereas other strains only show exaggerated bone loss after ovariectomy (OVX) and a blunted response to estrogens (Aguirre et al. 2001, Armour et al. 2001, Grassi et al. 2006). Treatment with NO-generating agents and NO-independent soluble GC activators prevents bone loss from estrogen deficiency and type 1 diabetes, respectively (Wimalawansa et al. 1996, Wimalawansa 2000, Jamal et al. 2004, Nabhan \& Rabie 2008, Kalyanaraman et al. 2017, 2018b).

We have shown in vitro that PKG1 and 2 are both targets of NO and cGMP in osteoblasts and osteocytes, with largely distinct functions: PKG2 mediates pro-proliferative effects of insulin and mechanical stimulation, while PKG1 and 2 both mediate pro-survival effects of estrogens via distinct mechanisms (Rangaswami et al. 2009, 2010, Marathe et al. 2012, Kalyanaraman et al. 2018b). PKG2 regulates nuclear translocation of $\beta$-catenin, a transcriptional co-activator downstream of the Wnt co-receptor low-density lipoprotein receptor-related protein-5 (LRP5), which plays a central role in skeletal homeostasis (Rangaswami et al. 2012, Baron \& Kneissel 2013, Kalyanaraman et al. 2017). NO and cGMP also regulate osteoclast motility and acid secretion via PKG1; however, some NO effects in bone are cGMP independent (van't Hof \& Ralston 2001, Wimalawansa 2007, Kalyanaraman et al. 2018a).

To examine the role of PKG2 in post-natal bone acquisition, independently of its function in endochondral bone formation, we established transgenic mice expressing a novel PKG2 mutant with increased basal kinase activity under control of the $2.3 \mathrm{~kb}$ Col1a1 promoter; the promoter is specific for cells of osteoblast lineage and has no detectable activity in osteoclasts (Dacquin et al. 2002, Kalajzic et al. 2002). The transgenic mice exhibited gender-specific increases in trabecular bone volume and Wnt/ $\beta$-catenin-related gene expression in bone. We detected higher NO and cGMP concentrations in serum and osteoblasts from female compared to male mice, which at least partly explain the sexually dimorphic skeletal phenotype of Col1a1-Prkg2 ${ }^{\mathrm{RQ}}$ transgenic mice. To avoid the influence of estrogen on NO/cGMP/PKG signaling, we then focused on male mice and found that male transgenic mice are protected from diabetes-induced bone loss.

\section{Materials and methods}

\section{Materials}

Antibodies against Akt, Akt(pSer $\left.{ }^{473}\right), \quad$ Erk1(pTyr $\left.{ }^{204}\right)$, GSK-3 $\beta\left(\right.$ pSer $\left.^{9}\right)$, vasodilator-stimulated phosphoprotein (VASP) (pSer ${ }^{239}$ ), NOS-3(pSer $\left.{ }^{1177}\right)$, caveolin-1 and cleaved caspase-3 were from Cell Signaling Technology. Antibodies against PKG2 and $\beta$-catenin and FITC-labeled secondary antibodies were from Invitrogen. A second monoclonal mouse antibody against PKG2, and a $\beta$-actin antibody were from Santa Cruz Biotechnology. 8-(4-chlorophenylthio)cGMP (8-pCPT-cGMP) was from BioLog. The IP3-receptor peptide GRRESLTSFG was synthesized by Eton Bioscience.

\section{Generation of Col1a1-Prkg2RQ transgenic mice}

A $2.3 \mathrm{~kb}$ segment of the mouse type Ia collagen (Col1a1) promoter, including the transcription start site and a short 5'-untranslated sequence (Kalajzic et al. 2002), was amplified by PCR using the following primers: 5'-attCCTAGGCTGCCTCTGCTTCTGTTCCA-3' and 5'-aatgcggccgcATGCCACGTGTAAAGG-3' (including a NotI fusion site). A rat Prkg2 CDNA encoding PKG2 with a $\mathrm{R} 242 \mathrm{Q}$ mutation (hereafter referred to as $P r k g 2^{\mathrm{RQ}}$ or PKG2 ${ }^{\mathrm{RQ}}$ ) was generated by site-directed mutagenesis (Zhao et al. 2005). We did not add an N-terminal epitope tag to avoid problems with enzyme mis-localization (Vaandrager et al. 1996), and we found that C-terminal tags reduce kinase activity. The Col1a1-Prkg2RQ transgenic construct was generated by fusing the $2.3 \mathrm{~kb}$ Colla1 promoter with the entire coding sequence of the rat $P r k g 2^{\mathrm{RQ}} \mathrm{cDNA}$, followed by a SV40 polyadenylation sequence. The construct was sequenced, and purified DNA micro-injected into pronuclei of fertilized eggs from C57BL/6 mice. Presence of the transgene in offspring was detected by PCR analysis of tail DNA using the primers 5'CGAGCCGAAAGAGTCTACA3' (F1) and 5'GTCTTGAAGTCCTCGCGCTCATGG3' (R1). Mice hemizygous for the Col1a1-Prkg2 ${ }^{\mathrm{RQ}}$ transgene were 
bred with WT C57BL/6 mice from Harlan (Cumberland, IN, USA).

\section{Animal experiments}

All mouse experiments were approved by the Institutional Animal Care and Use Committee of the University of California, San Diego. Mice were housed in a temperaturecontrolled environment with a 12-h light/darkness cycle and ad libitum access to water and food (Teklad Rodent Diet \#8604). To induce insulin deficiency (type 1 diabetes), 6-week-old WT $(n=18)$ and transgenic $(n=16)$ male litter mates were randomly assigned to receive two intraperitoneal injections of streptozotocin (STZ, $100 \mathrm{mg} / \mathrm{kg} / \mathrm{d}$ ) or vehicle on two consecutive days (after $4 \mathrm{~h}$ of fasting). Twelve days later, glucose was measured in tail vein blood and mice with blood glucose concentrations $\geq 15 \mathrm{mM}$ were considered diabetic; three STZ-injected mice with glucose $<15 \mathrm{mM}$ were excluded. Double calcein labeling was performed by intraperitoneal injection of calcein $(25 \mathrm{mg} / \mathrm{kg})$ at 7 and 2 days before killing by $\mathrm{CO}_{2}$ intoxication and exsanguination.

\section{Primary osteoblast cultures and proliferation assays}

Primary osteoblasts (POBs) were isolated from femurs and tibiae of 8-week-old mice and were cultured as described (Kalyanaraman et al. 2014). To induce differentiation, cells were plated at high density, and after confluency were switched to medium with $0.3 \mathrm{mM}$ sodium ascorbate and $10 \mathrm{mM} \beta$-glycerophosphate. Each POB preparation was characterized by alkaline phosphatase (ALP) staining and mineralization capacity as described (Kalyanaraman et al. 2014); cells were used at passages 1-3 and counted using a T20 automated cell counter (BioRad). Metabolically active osteoblasts were quantified using a CellTiter 96 $\mathrm{AQ}_{\text {ueous }}$ Cell Proliferation Assay Kit (Promega): after $16 \mathrm{~h}$ in medium with $0.1 \%$ FBS, cells were stimulated with $10 \%$ FBS for $24 \mathrm{~h}$ and tetrazolium (MTS) reduction to formazan was measured spectrophotometrically during the last $4 \mathrm{~h}$.

\section{Bone marrow stromal cell (BMSC) cultures}

Bone marrow mononuclear cells were plated at $4 \times 10^{5} \mathrm{cells} / \mathrm{cm}^{2}$ in RPMI 1640 with $10 \%$ FBS and 10\% horse serum (Joshua et al. 2014). After 7 days, adherent cells were switched to $\alpha$-MEM supplemented with $10 \%$ FBS $10 \%$ horse serum, $0.3 \mathrm{mM}$ sodium ascorbate and $10 \mathrm{mM} \beta$-glycerolphosphate to induce differentiation. ALP and Alizarin Red staining was performed 14 and
21 days later, respectively; colonies were counted and stained area was quantified by ImageJ (Joshua et al. 2014, Kalyanaraman et al. 2014).

\section{PKG2 purification and activity assays}

WT PKG2 and mutant PKG2RQ were expressed with N-terminal Flag epitope-tags in transiently-transfected 293T cells, purified on anti-Flag beads and eluted with Flag peptide (Kalyanaraman et al. 2014). Kinase activity was measured using the synthetic peptide GRRESLTSFG and $\left[\gamma^{32} \mathrm{P}\right] \mathrm{ATP}$ in the absence and presence of cGMP (Zhao et al. 2005). POB plasma membranes were isolated by density-gradient centrifugation (Kalyanaraman et al. 2014).

\section{Quantitative RT-PCR}

After removing growth plates and bone marrow, bone shafts were snap-frozen and pulverized. RNA was purified with RNeasy Mini-Kit columns (Qiagen). Quantitative RT-PCR was performed with $300 \mathrm{ng}$ of RNA as described (Kalyanaraman et al. 2017). All primers (Supplementary Table 1 , see section on supplementary data given at the end of this article) were tested with serial cDNA dilutions. Genes of interest were normalized to three different reference genes: $18 \mathrm{~S}$ rRNA, Hprt and $82 \mathrm{~m}$. The mean $\triangle \mathrm{CT}$ obtained for control WT mice was used to calculate the fold change in mRNA expression in the transgenic group using the $\Delta \Delta \mathrm{CT}$ method; for each mouse, the fold change in mRNA expression obtained using the different reference genes was averaged.

\section{Western blotting, immunofluorescence and immunohistochemical staining}

Western blots were generated using horseradish peroxidaseconjugated secondary antibodies detected by enhanced chemiluminescence (Rangaswami et al. 2009). POBs plated on glass coverslips were fixed in $4 \%$ paraformaldehyde, permeabilized with $1 \%$ Triton-X-100 and incubated with PKG2 antibody (1:100) or cleaved caspase-3-specific antibody (1:100 dilution), followed by a secondary FITCconjugated antibody. Nuclei were counterstained with Hoechst 33342, and images were analyzed with a Keyence BZ-X700 fluorescence microscope.

Tibiae were fixed overnight in $10 \%$ formalin, decalcified in $0.5 \mathrm{M}$ EDTA ( $\mathrm{pH}$ 7.5) for 5 days and embedded in paraffin. Eight micrometer sections were de-paraffinized in xylene and rehydrated in graded 
ethanol and water. For antigen retrieval, slides were placed in $10 \mathrm{mM}$ sodium citrate buffer $(\mathrm{pH} 6.0)$ at $80-85^{\circ} \mathrm{C}$ and allowed to cool to room temperature for $30 \mathrm{~min}$. Endogenous peroxidase activity was quenched in $3 \% \mathrm{H}_{2} \mathrm{O}_{2}$ for $10 \mathrm{~min}$. After blocking with 5\% normal goat serum, slides were incubated overnight at $4^{\circ} \mathrm{C}$ with anti-PKG2 antibody (1:100), followed by a horseradish peroxidaseconjugated secondary antibody. After development with 3-diaminobenzidine (Vector Laboratories), slides were counterstained with hematoxylin.

\section{Quantitation of $\mathrm{NO}_{x}$ and cGMP}

NO production was measured as the sum of nitrite and nitrate accumulation in the medium or serum, using a twostep colorimetric assay as described (Kalyanaraman et al. 2018b). cGMP concentrations were measured using an ELISA kit according to the manufacturer's protocol (Biomedical Technologies).

\section{Micro-CT}

Ethanol-fixed tibiae were analyzed according to established guidelines (Bouxsein et al. 2010), using a Skyscan 1076 (Skyscan, Belgium) scanner at $9 \mu \mathrm{m}$ voxel size, and applying an electrical potential of $50 \mathrm{kVp}$ and current of $200 \mathrm{~mA}$, with a $0.5 \mathrm{~mm}$ aluminum filter as described (Kalyanaraman et al. 2017). Mineral density was determined by calibration of images against $2 \mathrm{~mm}$ diameter hydroxyapatite rods $\left(0.25\right.$ and $\left.0.75 \mathrm{~g} / \mathrm{cm}^{3}\right)$. Cortical bone was analyzed by automatic contouring $3.6-4.5 \mathrm{~mm}$ distal to the proximal growth plate, using a global threshold to identify cortical bone, and eroding one pixel to eliminate partial volume effects. Trabecular bone was analyzed by automatic contouring of the proximal tibial metaphysis $(0.36-2.1 \mathrm{~mm}$ distal to the growth plate), using an adaptive threshold to select the trabecular bone (Kalyanaraman et al. 2017).

\section{Histomorphometry}

Femurs were fixed in 70\% ethanol, dehydrated and embedded in methyl methacrylate and sectioned at the University of Alabama Center for Metabolic Bone Disease. Masson's Trichrome-stained sections were used for static parameters, and unstained sections were used to assess fluorochrome labeling. Slides were scanned with a Hamamatsu Nanozoomer 2.0 HT Slide Scanning System (Hamamatsu Corporation), and image analysis was performed using the Nanozoomer Digital Pathology NDP view2 software. Trabecular bone was analyzed between 0.25 and $1.25 \mathrm{~mm}$, and cortical bone between 0.25 and $5 \mathrm{~mm}$ proximal to the growth plate by an observer blinded to the genotype of the mice (Joshua et al. 2014).

\section{Statistical analyses}

GraphPad Prism5 was used for two-tailed Student $t$-test (to compare two groups) or one-way ANOVA with Bonferroni post-test (to compare more than two groups); $P<0.05$ was considered significant. When analyzing bone microarchitecture in diabetic mice, we tested the following primary and secondary hypotheses by two-sided t-test: (i) Transgenic animals are protected from diabetic bone loss; (ii) WT diabetic animals have lower bone mass compared to non-diabetic WT animals and (iii) transgenic animals have higher bone mass compared to WT animals.

\section{Results}

\section{Generation of transgenic mice with expression of a mutant PKG2 ${ }^{\mathrm{R} 242 \mathrm{Q}}$ from the Col1a1 promoter (Col1a1-Prkg2RQ)}

To delineate in vivo functions of PKG2 in osteoblasts, we introduced a mutation in the first cGMP binding domain of PKG2, homologous to a gain-of-function mutation in PKG1 associated with human thoracic aortic aneurysms and dissections (Guo et al. 2013). In contrast to the R177Q mutation in PKG1 - which causes nearly complete activation and renders the enzyme largely cGMP-unresponsive (Guo et al. 2013) - the PKG2 R242Q mutation increased basal activity of the purified enzyme only about four-fold, to $<10 \%$ of maximal cGMPstimulated activity (Fig. $1 \mathrm{~A}$ and $\mathrm{B}$ and Supplementary Fig. 1A). Both mutations are located in the first cGMP binding pocket and likely disrupt interaction between inhibitory and catalytic domains, but the relative cGMP affinities of the first and second cGMP binding pockets are reversed between PKG1 and 2 (Vaandrager et al. 2005) - the first cGMP binding site in PKG2 is a low affinity, rapidly-dissociating site, which may explain the less dramatic effect of the mutation in PKG2.

The mutant PKG2 ${ }^{\mathrm{RQ}}$ was cGMP responsive with a similar cGMP affinity as the WT enzyme $\left(\mathrm{K}_{\mathrm{a}}=0.4\right.$ and $0.45 \mu \mathrm{M}$, respectively). In addition, the mutant enzyme's affinity for a synthetic peptide substrate was similar to that of the WT enzyme (Supplementary Fig. 1B). We chose to express mutant $\mathrm{PKG} 2^{\mathrm{RQ}}$ under control of the murine 
A

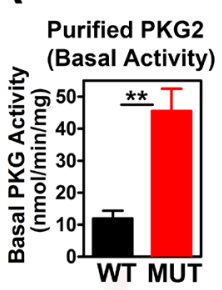

B

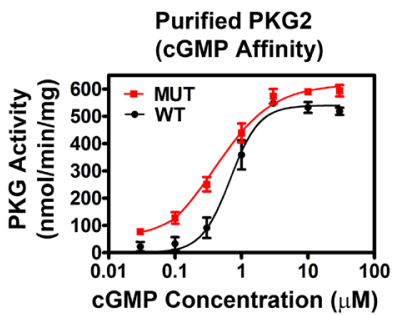

C

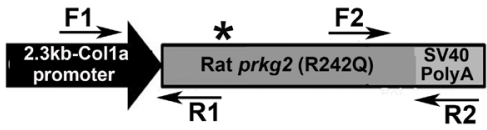

D

E

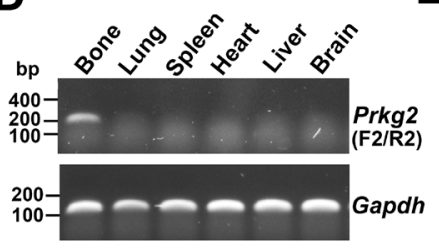

E

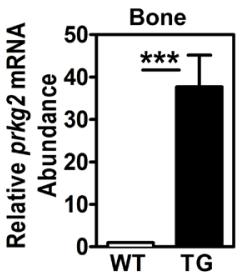

Prkg2 mRNA Expression
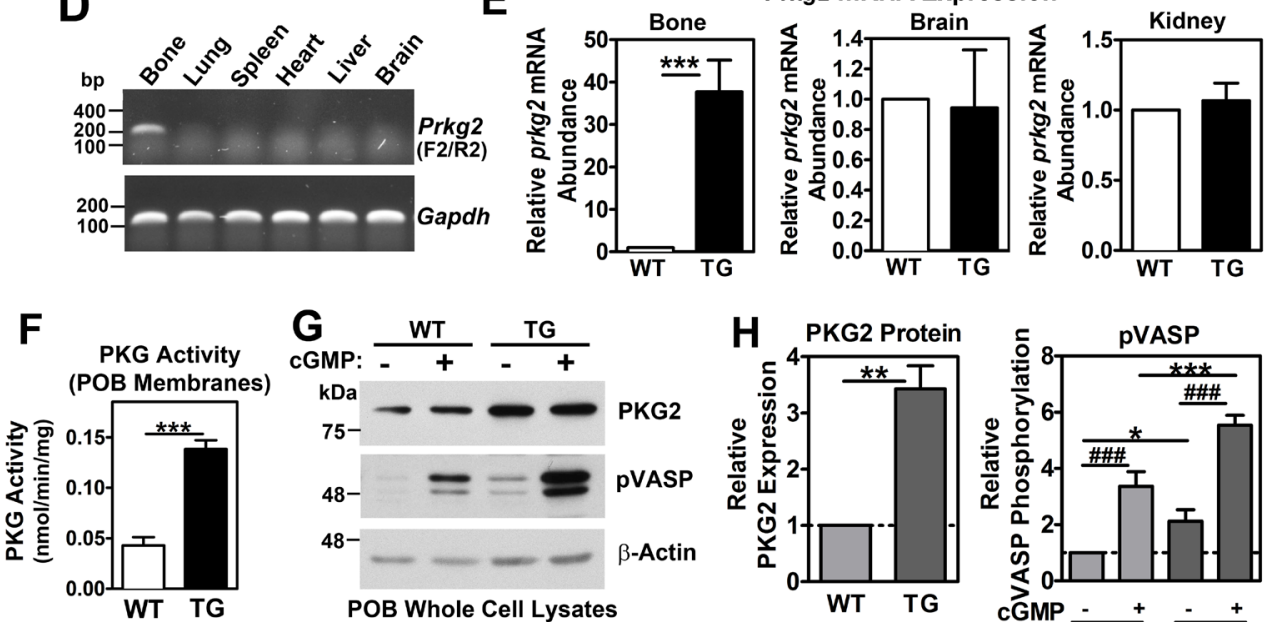

$\mathbf{G}$
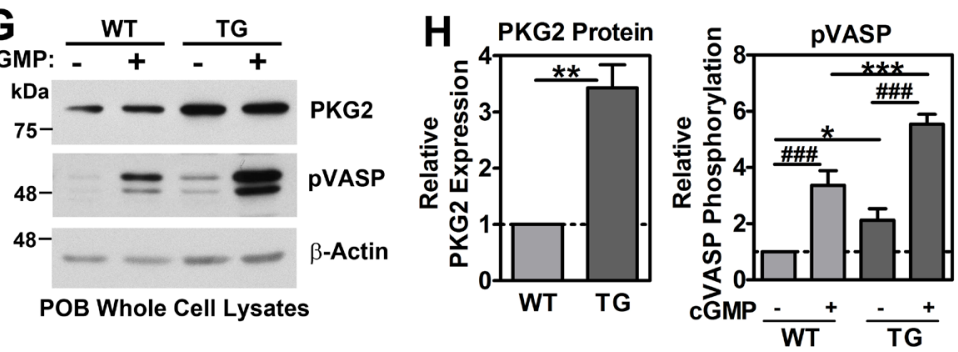

I

POBs: PKG2 Immunofluorescence (green)

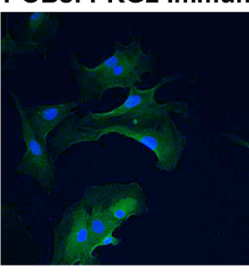

WT

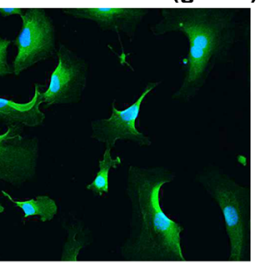

TG

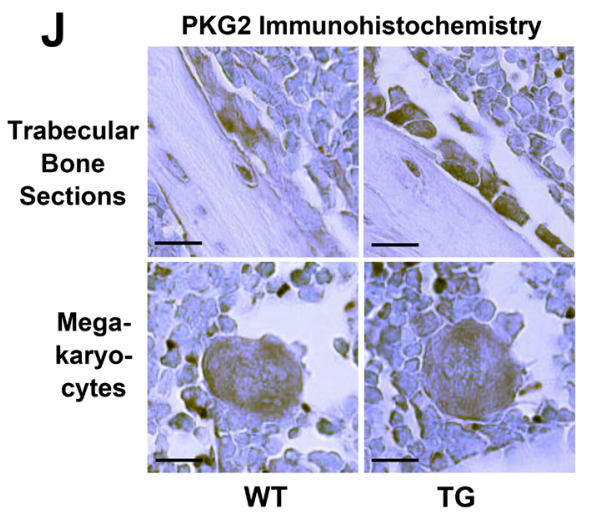

Figure 1

Characterization of osteoblast-specific PKG2RQ expression in transgenic Col1a1-Prkg2 $2^{R Q}$ mice. (A and B) WT and mutant PKG2 ${ }^{R Q}$ enzymes were affinitypurified from transfected 293T cells, and basal kinase activity was measured with a synthetic peptide in the absence of cGMP (A) or in the presence of increasing CGMP concentrations (B). (C) Scheme of the Col1a1-Prkg2 ${ }^{\mathrm{RQ}}$ construct used for injection into fertilized mouse eggs; the location of the R242Q mutation in the rat Prkg2 CDNA is indicated by an asterisk. The positions of PCR primers used for genotyping (F1/R1) or detection of transgenic mRNA (F2/R2) are shown by arrows. (D) RNA was extracted from the indicated organs of a transgenic mouse, and transgene-derived mRNA was detected by RT-PCR using the F2/R2 primer pair shown in C. No PCR signal was obtained when reverse transcriptase was omitted (not shown); Gapdh served as a control for RNA quality. (E) RNA was extracted from bone, brain, and kidney of WT and transgenic (TG) mice, and Prkg2 mRNA was quantified by qRT-PCR using primers recognizing both rat and mouse transcripts. Data were normalized to $\beta 2$-microglobulin $(B 2 \mathrm{~m})$ and calculated according to the $\Delta \Delta \mathrm{Ct}$ method, assigning the mean of the WT group a value of one. Data are means \pm S.E.M. from $n=10$ mice per genotype for bone $(5$ males and five females) and $n=4$ for brain and kidney ( $* * * P<0.001$ ). (F) Cell membranes were purified from primary osteoblasts (POBs) from WT and TG mice using a percoll gradient, and CGMP-stimulated PKG activity was measured (mean \pm s.E.M. of three independent experiments; $* * * P<0.001)$. (G and $H$ ) POBs from WT and TG mice were serum-starved and treated with $100 \mu \mathrm{M}$ 8-pCPT-cGMP (+cGMP) for $10 \mathrm{~min}$. The amount of PKG2 protein and phosphorylation of the PKG substrate VASP on Ser ${ }^{239}$ were assessed by Western blotting of whole cell lysates, with $\beta$-actin serving as a loading control (G). Results of three independent $\mathrm{POB}$ isolates per genotype were quantified by densitometry scanning (H). Data represent means \pm S.E.M. $\left({ }^{*} P<0.05, * * P<0.01, * * * P<0.001\right.$, and \#\#P<0.001 for the indicated comparisons). (I) Immunofluorescence staining for PKG2 (green) in POBs isolated from WT and TG mice (nuclei counterstained with Hoechst 33342). (J) Immunohistochemical staining for PKG2 in tibial sections from WT and TG mice; top panels show osteoblasts on trabecular surfaces, bottom panels show megakaryocytes, which served as a positive control $(\mathrm{bar}=20 \mu \mathrm{m})$. I and J are representative of POBs and bones from three mice per genotype. 
$2.3 \mathrm{~kb}$ Col1a1 promoter, because the latter is active in cells of the osteoblastic lineage, starting from committed mesenchymal stem cells through mature osteocytes (Dacquin et al. 2002, Kalajzic et al. 2002). One of several transgenic founder lines was further characterized (Line Fe-9, Supplementary Fig. 1C).

\section{Osteoblast-specific PKG2RQ expression in Col1a1-Prkg2RQ transgenic mice}

PCR analysis of reverse-transcribed RNA extracted from multiple organs showed amplification of a specific, $210 \mathrm{bp}$ band corresponding to the transgene-derived Prkg2 $2^{\mathrm{RQ}}$ mRNA in bone, but not in other organs (Fig. 1D); this band was not detected in the absence of reverse transcriptase, thus excluding genomic DNA contamination. Using a primer pair recognizing both mouse (endogenous) and rat (transgenic) Prkg2 transcripts, we found that the transgenic transcript was expressed $\sim 35$-fold higher in bone from transgenic mice compared to the endogenous Prkg2 transcript in WT mice. In contrast, WT and transgenic mice showed similar Prkg2 mRNA expression in brain and kidney, two organs with high endogenous PKG2 mRNA expression (Vaandrager et al. 2005) (Fig. 1E).

SincePKG2 associates with plasma membranes, whereas PKG1 is predominantly cytoplasmic (Vaandrager et al. 1996, Hofmann et al. 2009, Rangaswami et al. 2009), we measured PKG activity in purified plasma membranes of primary osteoblasts (POBs) isolated from WT and transgenic mice. cGMP-stimulated PKG activity was only about three-fold higher in plasma membranes from transgenic compared to WT mice, correlating with an increased amount of PKG2 protein (Fig. $1 \mathrm{~F}$ and Supplementary Fig. 1D). We could not reliably determine basal PKG2 activity in the absence of cGMP using this kinase assay, because available PKG inhibitors are not effective against the mutant PKG2, and the synthetic peptide can be phosphorylated by other membrane-associated kinases. Using a second PKG2-specific antibody, approximately three-fold more PKG2 protein could be detected in whole cell lysates of transgenic compared to WT POBs (Fig. 1G and $\mathrm{H})$. Correspondingly, phosphorylation of VASP on Ser239, a site specifically targeted by PKG1 and 2, was increased in transgenic compared to WT POBs, both in the absence and presence of cGMP (representing basal and maximal PKG activity, respectively) (Fig. $1 \mathrm{G}$ and $\mathrm{H})$. Immunofluorescence staining of PKG2 in POBs from transgenic mice was considerably brighter than that of WT POBs (Fig. 1I). Immunohistochemical staining of bone sections showed a stronger signal in bone-lining osteoblasts in the transgenic compared to WT mice (Fig. 1J; transgenic mice had more bone-lining osteoblasts than WT mice; described below and shown in Fig. 5D). However, staining of endogenous PKG2 in megakaryocytes was similar between transgenic and WT animals (Fig. 1J). Thus, Col1a1-Prkg2RQ mice express the mutant PKG2 in osteoblasts, leading to a moderate increase in both basal and cGMP-stimulated PKG2 activity.

Increased proliferation, Erk and Akt/GSK-3/

$\beta$-catenin signaling in POBs from Col1a1-Prkg2RQ transgenic mice

$\mathrm{NO} / \mathrm{cGMP}$ activation of PKG is required for osteoblasts to proliferate in response to insulin or mechanical stimulation (Rangaswami et al. 2010, Kalyanaraman et al. 2018b). To examine whether expression of PKG2RQ in osteoblasts affects proliferation, we compared multiple POB cultures that were independently established from 8 week-old Col1a1-Prkg2RQ transgenic mice and their WT litter mates. The population doubling time of male transgenic POBs was $1.5 \pm 0.1$ day compared to $3.2 \pm 0.9$ day for WT cells (Fig. 2A). We also quantified metabolically-active cells after $24 \mathrm{~h}$ of serum stimulation by MTS reduction to formazan. Male transgenic POBs reduced 45\% more MTS than WT POBs (Fig. 2B). For comparison, POBs isolated from female transgenic mice reduced 18\% more MTS than POBs from female WT litter mates (Supplementary Fig. 2A).

PKG activation by NO/cGMP in osteoblasts leads to activation of ERK and Akt via Src: PKG2 directly phosphorylates and stimulates the phosphatase SHP-1, which de-phosphorylates Src on an inhibitory site (Rangaswami et al. 2010, 2012). In contrast, PKG2 inactivates GSK-3 $\beta$ both directly, via phosphorylation of a negative-regulatory site, and indirectly, via Akt activation (Rangaswami et al. 2012, Kalyanaraman et al. 2017). To assess effects of transgenic PKG2RQ expression on ERK, Akt, and GSK-3 $\beta$ phosphorylation, we compared three independent POB lines of male and female WT and transgenic mice (12 lines total). POBs from male transgenic mice showed significantly higher basal ERK and Akt phosphorylation, and higher cGMP-stimulated ERK, Akt, and GSK-3 $\beta$ phosphorylation compared to POBs from male WT littermates (Fig. 2C, D, E and F). In POBs from female transgenic mice, cGMP-induced ERK phosphorylation was also increased, but Akt and GSK-3 $\beta$ showed only a trend toward increased phosphorylation compared to female WT mice, and basal phosphorylation was the same between both genotypes in the females (Supplementary Fig. 2B, C, D and E). As described above, 
A
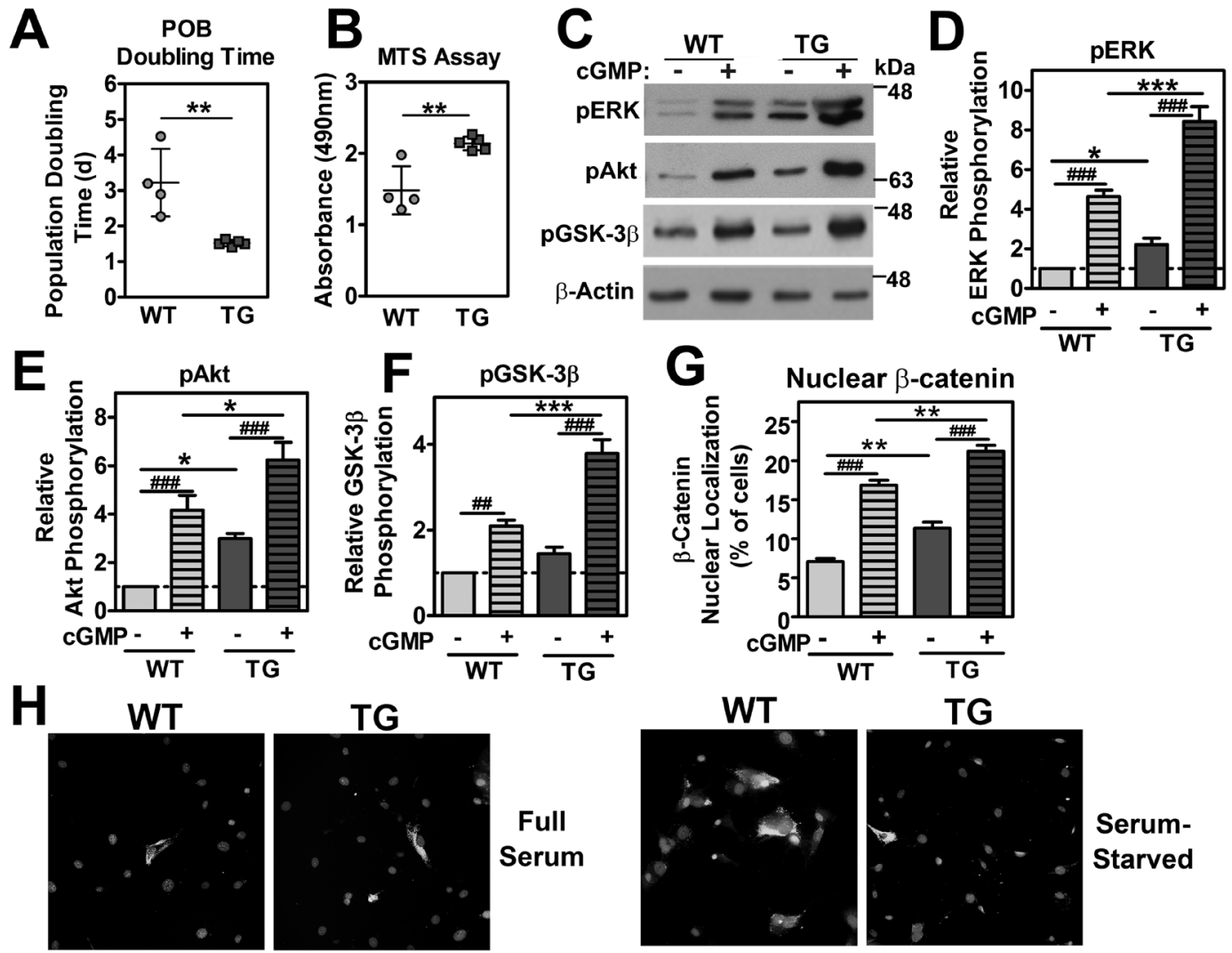

TG

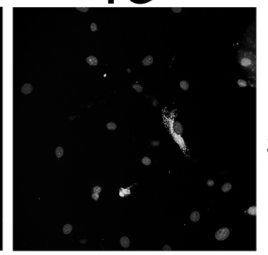

Full

Serum

$9.02+0.19 \%$

$6.28+1.25 \%$
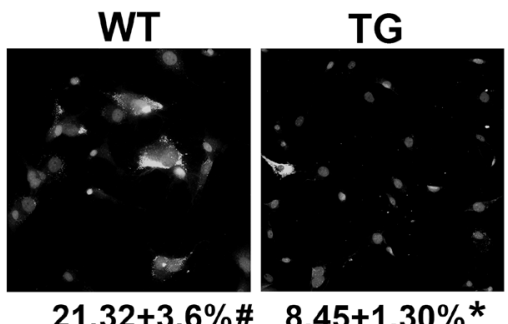

Serum-

Starved

Apoptotic Cells Positive for Cleaved Caspase-3 (Green)
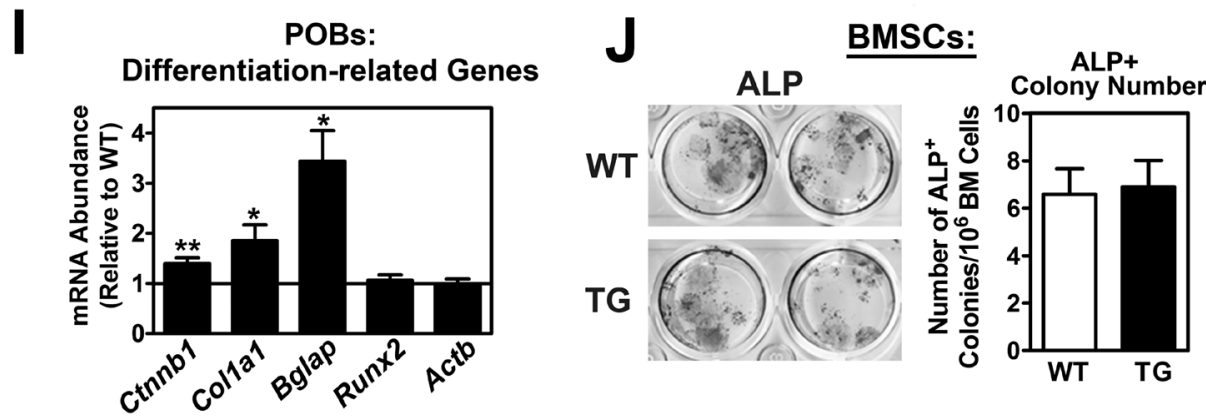

Figure 2

Proliferation, Erk and Akt/GSK3/ $\beta$-catenin signaling, survival, and differentiation of POBs isolated from male Col1a1-Prkg2RQ transgenic and WT POBs. POBs were isolated from eight week-old male transgenic $(T G, n=5)$ and WT $(n=4)$ mice. (A and B) Cells were plated at $1.2 \times 10^{5}$ cells/cm² and were counted $72 \mathrm{~h}$ later to calculate population doubling times (A). Metabolically-active cells were quantified by MTS reduction as described in Methods (B). Each data point represents the mean of three independent experiments performed with POBs from one mouse at passage 2 (lines show means \pm s.D.; $* * P<0.01)$. (C, D, E and F) Serum-deprived POBs were treated with vehicle or $100 \mu \mathrm{M} 8$-pCPTcGMP (+cGMP) for 10 min. Western blots of cell extracts were analyzed with phospho-specific antibodies for ERK1/2-(pTyr $\left.{ }^{204}\right)$, Akt(pSer $\left.{ }^{473}\right)$, or GSK3 $\beta(p S e r 9)$; $\beta$-actin served as a loading control. Bar graphs summarize results from three independent $\mathrm{POB}$ isolates per genotype. (G) Nuclear localization of $\beta$-catenin was determined by immunofluorescence staining of POBs isolated from three male mice per genotype. Bar graphs (D-G) show means \pm s.E.M., $* P / \# P<0.05$, $* * P / \# \#<0.01$, and $* * * P / \# \# \#<0.001$ for the indicated comparisons. (H) POBs were serum-starved for $24 \mathrm{~h}$ or kept in normal growth medium; apoptosis was detected by immunofluorescence staining for cleaved caspase-3 (green, nuclei counterstained with Hoechst 33342). The percentage of cells staining positive for cleaved caspase-3 is shown below (means \pm S.E.M. of three independent experiments; $\# P<0.05$ for comparison to WT in full serum, and $* P<0.05$ for comparison to WT serum-starved). (I) RNA was extracted from confluent POBs cultured in differentiation medium for 14 day; osteoblast differentiation-related transcripts were quantified by qRT-PCR and normalized to three housekeeping genes $(18 \mathrm{~S}$, hprt, and $b 2 \mathrm{~m})$. Data were calculated according to the $\Delta \Delta \mathrm{Ct}$ method, with the mean of the WT group for each gene assigned a value of one. Gene names: Ctnnb1 ( $\beta$-catenin), Col1a1 (collagen 1a1), Bglap (osteocalcin), and Actb ( $\beta$-actin). (J) Bone marrow mononuclear cells from eight week-old male TG and WT mice ( $n=5$ mice of each genotype) were plated at $4 \times 10^{5}$ cells/ $/ \mathrm{cm}^{2}$, and adherent BMSCs were switched to osteoblastic differentiation medium. After 14 day, BMSC colonies were stained for ALP activity; the number of ALP+ colonies per well was counted and expressed per $10^{6}$ bone marrow cells plated (means \pm S.E.M.; $* P<0.05$ and ${ }^{*} * P<0.01$ for comparison to WT). 
PKG2 expression was similar in male and female transgenic POBs (Fig. 1G and Supplementary Fig. 2B).

PKG2 directly and indirectly (via Akt activation) inhibits GSK-3 $\beta$, thereby regulating $\beta$-catenin stability and nuclear translocation (Zhao et al. 2005, Rangaswami et al. 2012, Kalyanaraman et al. 2017). In POBs from male Col1a1-Prkg2 ${ }^{R Q}$ transgenic mice, more nuclei stained positive for $\beta$-catenin, under both basal and cGMP-stimulated conditions, compared to cells from WT mice (Fig. 2G). In contrast, POBs isolated from female transgenic and WT mice showed similar nuclear $\beta$-catenin staining under both basal and cGMP-stimulated conditions (Supplementary Fig. 2F). However, the number of $\beta$-catenin-positive nuclei was almost twice as high in unstimulated female compared to male WT POBs (Fig. 2G and Supplementary Fig. 2F). Interestingly, when basal NO synthesis in female WT POBs was inhibited with $\mathrm{N}(\omega)$ nitro-l-arginine methyl ester (L-NAME), the percentage of $\beta$-catenin-positive nuclei was reduced to levels found in male cells (Supplementary Fig. 2G). These data confirm that nuclear localization of $\beta$-catenin is under control of NO (Kalyanaraman et al. 2017), and suggest a higher level of basal $\beta$-catenin signaling in female compared to male osteoblasts, which appears to obscure the PKG2RQ effect on $\beta$-catenin in female cells (Supplementary Fig. 2F).

\section{Apoptosis resistance and enhanced expression of osteoblast differentiation-associated genes in POBs and BMSCs from male Col1a1-Prkg2RQ transgenic mice}

POBs from male Col1a1-Prkg2RQ transgenic mice showed enhanced survival after prolonged serum starvation: compared to WT cells, fewer transgenic POBs staining positive for cleaved caspase-3 (Fig. 2H). To examine osteoblast differentiation, POBs from WT and transgenic mice were plated at high density, and switched to differentiation medium after reaching confluency. Differentiated POBs from male transgenic mice expressed higher amounts of mRNA encoding $\beta$-catenin (Ctnnb1), collagen-1 $\alpha$ (Col1a1), and osteocalcin (Bglap) compared to WT POBs, while expression of Runx2 and $\beta$-actin (Actb) was unchanged (Fig. 2I). However, POBs of both genotypes showed similar ALP activity and mineralization after 14 and $21 \mathrm{~d}$, respectively (Supplementary Fig. 3A and B).

To examine the effect of PKG2RQ expression on osteoblast progenitors, we cultured BMSCs from male WT and Col1a1-Prkg2 $2^{R Q}$ transgenic mice in osteoblastic differentiation medium. We found the same number and size of colonies staining positive for ALP activity, and the same degree of mineralization (Fig. 2J and Supplementary Fig. 3C). However, transgenic BMSCs expressed threefold more osteocalcin (Bglap) and two-fold more Runx2 mRNA, respectively, compared to WT BMSCs, suggesting a modest increase in osteoblastic differentiation potential (Supplementary Fig. 3D). The ratio of transgenic to endogenous Prkg2 mRNA expression in BMSCs was similar to that found in bone (Supplementary Fig. 3E; compare to Fig. 1E).

\section{Gender-specific differences in POB NO/cGMP generation and NO/cGMP serum concentrations}

Previous workers showed that estradiol acutely increases endothelial NO production via membrane-bound estrogen receptor(ER)- $\alpha$ stimulation of NO synthase-3 (Russell et al. 2000, Mendelsohn \& Karas 2010). Since POBs produce NO and cGMP constitutively (Rangaswami et al. 2009, Mendelsohn \& Karas 2010, Marathe et al. 2012, Joshua et al. 2014), we hypothesized that female POBs, which contain higher ER- $\alpha$ copy numbers than males (Chaudhri et al. 2014), may produce more NO than male cells. Indeed, female POBs produced about 1.5-fold more nitrites and nitrates (stable NO metabolites) per hour per $10^{6}$ cells compared to male POBs, and this correlated with increased phosphorylation of NOS-3 on Ser ${ }^{1179}$, a stimulatory site (Fig. 3A and B). Correspondingly, the intracellular cGMP concentration was 1.7-fold higher in female compared to male POBs (Fig. 3C).

Estrogen replacement therapy in postmenopausal women increases $\mathrm{NO}_{\mathrm{x}}$ and cGMP serum concentrations, and $24 \mathrm{~h}$ urinary cGMP excretion (Rosselli et al. 1995, Hayashi et al. 2000, Mueck et al. 2001). Moreover, $24 \mathrm{~h}$ urinary cGMP excretion in pre-menopausal women is higher than in age-matched men (Markovitz et al. 1997, Cui et al. 2009). However, to our knowledge, gender-specific differences in serum $\mathrm{NO}_{\mathrm{x}}$ and cGMP concentrations have not been examined. In eight week-old WT and Col1a1$\operatorname{Prkg} 2^{R Q}$ transgenic mice, we found that $\mathrm{NO}_{\mathrm{x}}$ and cGMP serum concentrations were $56 \%$ and $32 \%$ higher in female compared to male mice, respectively, with no significant difference between the two genotypes (Fig. 3D and E). Since PKG2 has a $K_{a}$ for cGMP of about $0.4 \mu M$ (Fig. 1B) (Vaandrager et al. 2005), a change in cGMP concentration from 60 to $80 \mathrm{nM}$ would be expected to increase PKG activity. These results suggest that females have higher endogenous PKG2 activities, at least in osteoblasts, but probably also in other tissues. 

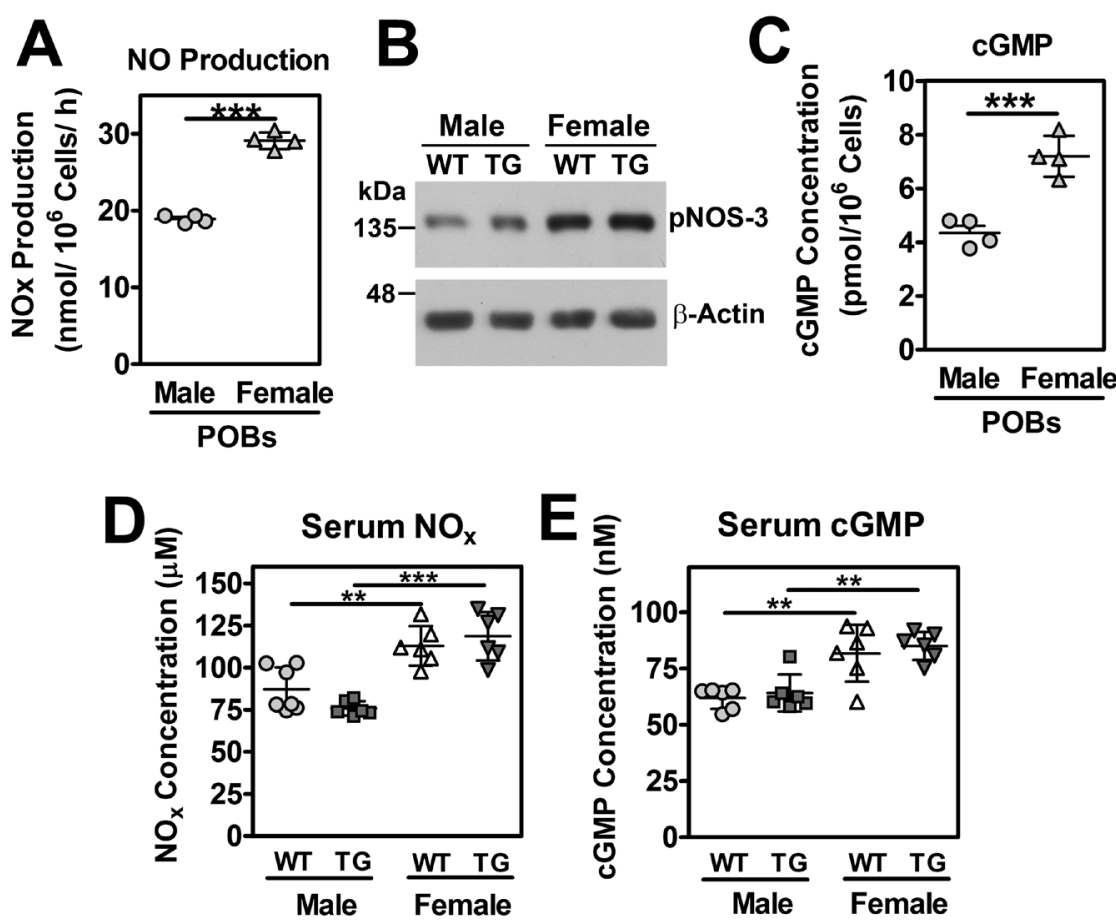

Figure 3

Gender-specific differences in serum NOx and CGMP concentrations in mice. (A, B and C) POBs were isolated from 8 week-old male or female WT mice ( $n=4$ each) and were plated at passage 3 at equal density. Cells were transferred to fresh medium for $1 \mathrm{~h}$ prior to measuring $\mathrm{NO}_{x}$ (indicating the sum of nitrate plus nitrite) in the medium by Griess reaction (A). NOS-3 phosphorylation on Ser ${ }^{1799}$ was assessed in cell extracts by Western blotting with a phosphospecific antibody (B). Intracellular cGMP concentrations were measured by ELISA (C). ( $D$ and $E$ ) Serum was obtained by cardiac puncture at the time of euthanasia from male and female WT and transgenic (TG) mice ( $n=6$ per group). $\mathrm{NO}_{x}$ and cGMP concentrations were quantified by Griess reaction and ELISA, respectively. Data represent means \pm S.D. $(* * P<0.01$ and $* * * P<0.001$ for the indicated comparisons).

\section{Increased trabecular bone mass in male Col1a1-Prkg2RQ transgenic mice}

Col1a1-Prkg2 $2^{R Q}$ transgenic mice were born at the expected Mendelian frequency, were indistinguishable from their WT littermates at birth, and showed no obvious skeletal abnormalities on plain X-Rays at eight weeks of age. They had similar body weights and tibial lengths as WT mice, although the male transgenics showed a trend toward increased body weight (+4\%, P=0.1) (Fig. 4A and B). Computed tomography analysis of tibial bone microarchitecture revealed that eight week-old male transgenic mice had increased BMD (+20\%), trabecular bone volume fraction $(+47 \%)$, trabecular number $(+27 \%)$, and trabecular thickness (+15\%) compared to male WT littermates (Fig. 4C and E). In contrast, no apparent differences in trabecular micro-architecture were found between female transgenic and WT mice at this age (Fig. 4D and F). Importantly, Prkg2 mRNA and PKG2 protein expression were the same in bones and POBs from male and female Col1a1-Prkg2RQ transgenic mice (data in Fig. 1F, G and $\mathrm{H}$ represent combined results from both sexes, but data were also analyzed separately). Cortical parameters (cortical bone area fraction, cross-sectional thickness and TMD) were the same in eight week-old transgenic and WT mice of both genders (Supplementary Fig. 4A and B).

\section{Increased bone formation parameters in male Col1a1-Prkg2RQ transgenic mice}

Consistent with the normal length of transgenic tibiae, femoral growth plate thickness was the same in male transgenic and WT littermates (Fig. 5A and B). These results confirm lack of biologically-significant PKG2RQ transgene expression in growth plate chondroblasts, and are in keeping with absence of Col1a1 promoter activity in the chondroblastic lineage (Dacquin et al. 2002, Kalajzic et al. 2002).

To determine the effect of PKG2RQ expression on bone formation parameters, we performed histomorphometric measurements in the distal femur after double calcein labeling. Eight week-old male transgenic mice showed dramatically increased trabecular mineralizing surface (MS/BS, +91\%), mineral apposition rate (MAR, +80\%), and bone formation rate (BFR, +234\%) compared to their male WT littermates, suggesting both increased osteoblast numbers and activity (Fig. 5C). Similar results were found on endocortical bone surfaces (Supplementary Fig. 5A). The number of osteoblasts on trabecular as well as endocortical surfaces was increased by $71 \%$ and $97 \%$, respectively, in male transgenic animals, while there was no change in osteoclast numbers (Fig. 5D and E). 


\begin{tabular}{l|l|l|c|c|}
$\begin{array}{l}\text { Journal of } \\
\text { Endocrinology }\end{array}$ & $\begin{array}{l}\text { Protein kinase G2 regulation of } \\
\text { bone formation }\end{array}$ & $\mathbf{2 3 8 : 3}$ \\
\hline
\end{tabular}

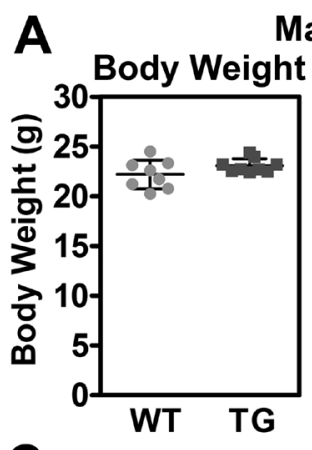

Males (8wk)

C
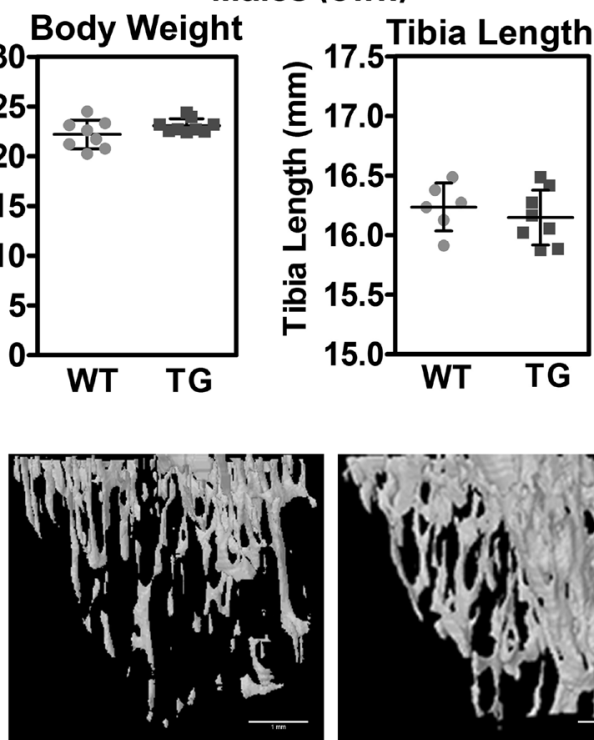

WT

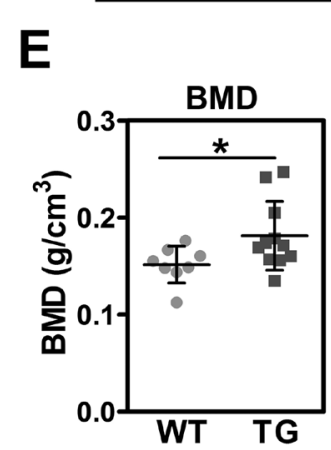

Males

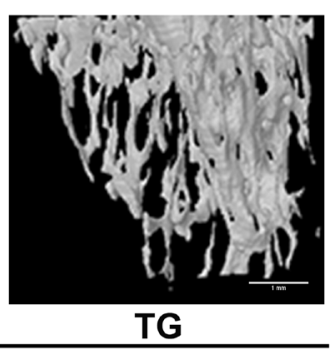

Bone Volume Fraction

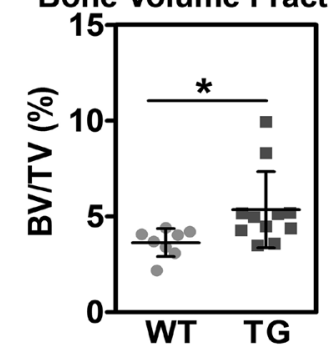

Trabecular Number
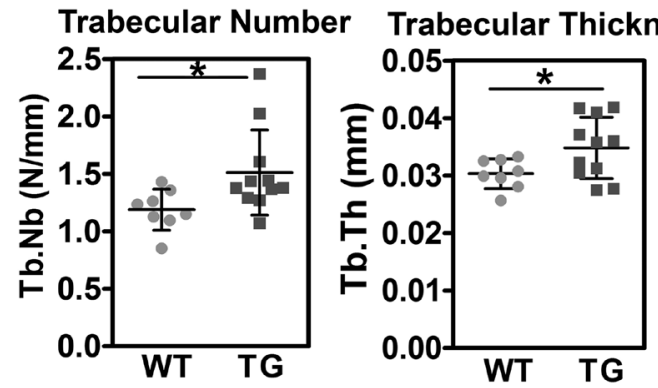

B

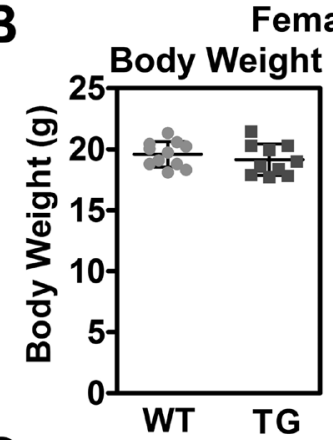

Females (8wk)

D
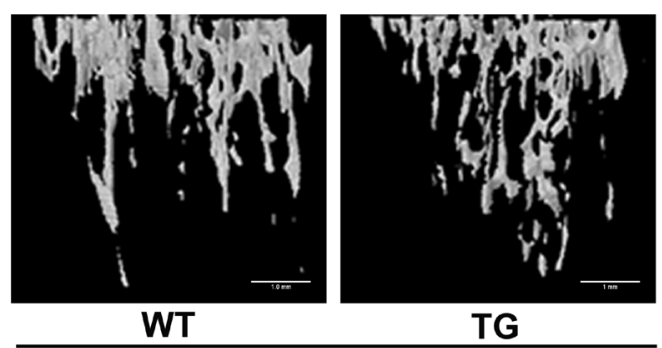

Females

$\mathbf{F}$
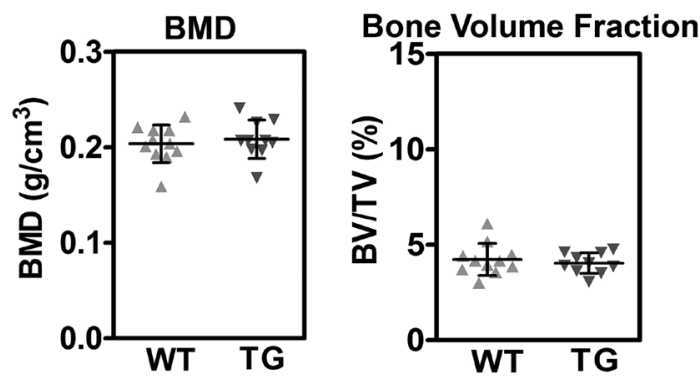

Trabecular Number Trabecular Thickness
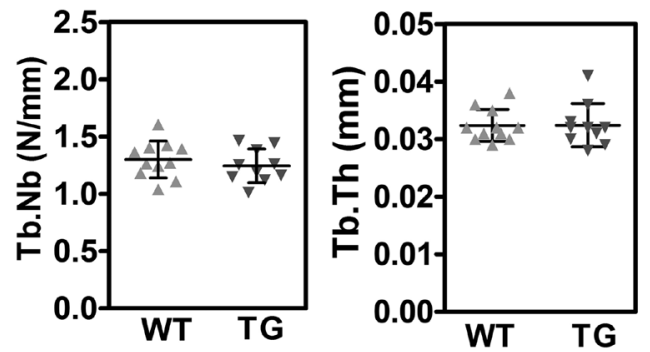

Figure 4

Increased trabecular bone mass in male, but not female Col1a1-Prkg2 ${ }^{R Q}$ transgenic mice. Male ( $\mathrm{A}, \mathrm{C}$ and $\left.\mathrm{E}\right)$ and female (B, D and F) transgenic (TG) mice and their WT litter mates were analyzed at eight weeks of age. (A and B) Body weight and tibia length are shown for each gender. (C and D) Tibiae were analyzed by micro-CT, with three-dimensional reconstruction of the trabecular bone at the proximal tibia below the growth plate shown. (E and $\mathrm{F}$ ) Trabecular BMD, trabecular bone volume fraction (BV/TV), trabecular number (Tb.N), and trabecular thickness (Tb.Th) were measured by micro-CT at the proximal tibia. Data represent means \pm s.D. (males: $n=8 \mathrm{WT}$ and $n=10 \mathrm{TG}$; females: $n=11 \mathrm{WT}$ and $n=10 \mathrm{TG}$ ). ${ }^{*} P<0.05$ for the indicated comparisons.

\section{Gender-specific increases in the expression of}

Wnt-related genes in male Col1a1-Prkg2RQ

transgenic mice

Pharmacologic activation of the NO/cGMP/PKG signaling cascade regulates the expression of Wnt-related genes in osteoblasts in vitro (Rangaswami et al. 2012, Kalyanaraman et al. 2017). In the tibiae of male WT and Col1a1-Prkg2RQ transgenic mice, mRNA expression of $\beta$-catenin (Ctnnb1), Wnt1, the Wnt co-receptor LRP5 (Lrp5), collagen-1 $\alpha$ (col1a1), and alkaline phosphatase $(A l p l)$ was increased two- to five-fold compared to 
A

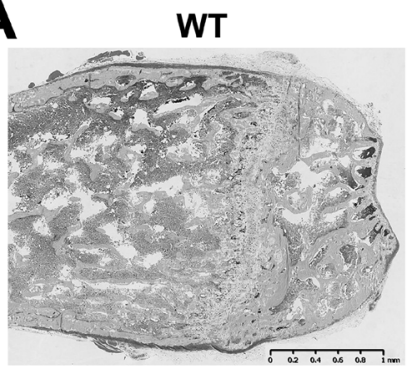

TG

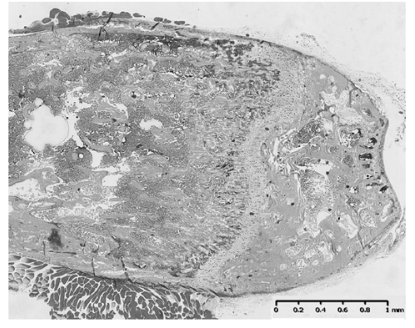

B Growth PlateThickness

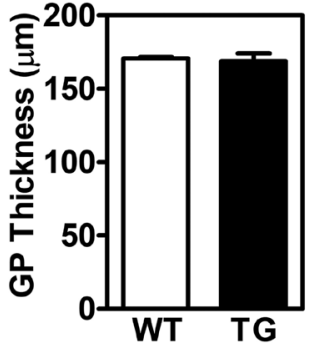

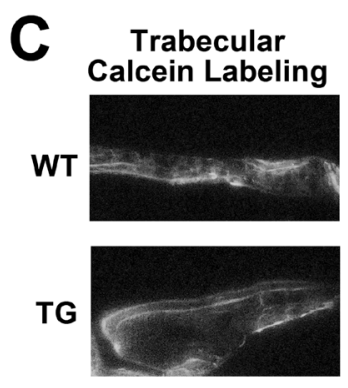
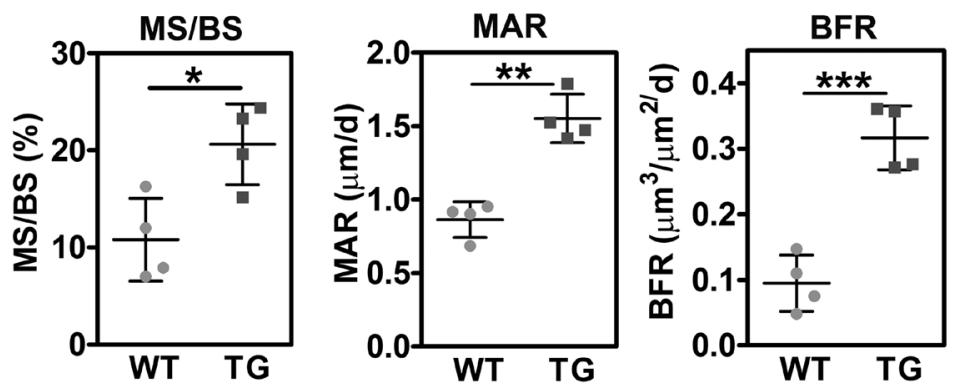

D

Osteoblast No.

(Trabecular)

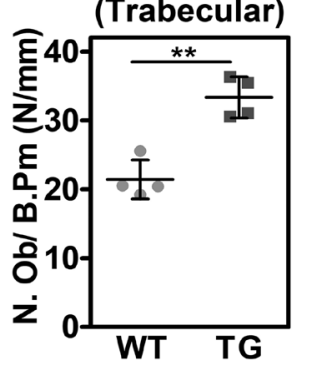

Osteoblast No.

(Cortical)

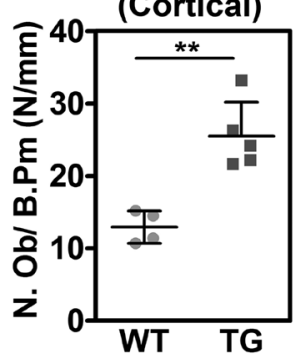

E

Osteoclast No.
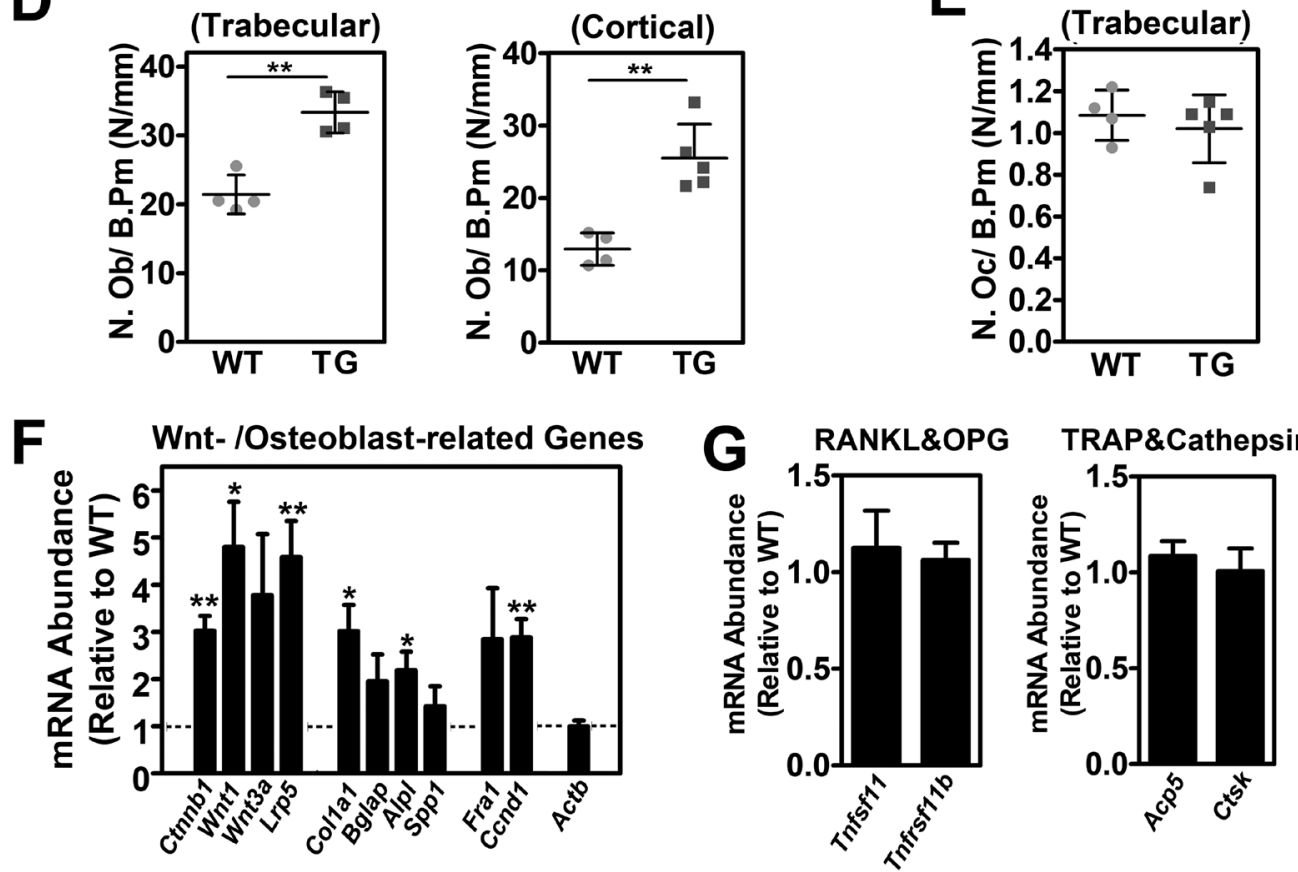

Figure 5

Increased bone formation and expression of Wnt-related genes in male Col1a1-Prkg2RQ transgenic mice. (A and B) Trichrome stains of distal femur sections were analyzed in 8 week-old male mice and the thickness of the growth plate was measured in the center and at three equally spaced points on each side ( $n=4 \mathrm{WT}$ and $n=5 \mathrm{TG}$ ). (C) Eight week-old males received calcein injections 7 and $2 \mathrm{~d}$ prior to euthanasia, and trabecular calcein labeling was assessed by fluorescence microscopy. Mineralizing surfaces (MS/BS), MAR, and BFR were measured at trabecular surfaces between 0.25 and $1.25 \mathrm{~mm}$ proximal to the femoral growth plate. (D and E) Osteoblasts (D) were counted on femoral trabecular and endocortical surfaces, osteoclasts (E) on trabecular surfaces. Panels C, D and E show means \pm s.D. of $n=4$ WT and $n=5$ TG mice; ${ }^{*} P<0.05$ and $* * P<0.01$ by two-sided $t$-test. (F and G) RNA was extracted from tibial shafts, and the relative abundance of Wnt-losteoblast- and RANKL- or osteoclast-related transcripts was quantified by qRT-PCR and normalized to three different housekeeping genes (18S, Hprt, and B2m). Data were calculated according to the $\Delta \Delta \mathrm{Ct}$ method, with the mean of the WT group for each gene assigned a value of one. Gene names: Ctnnb1 ( $\beta$-catenin), Bglap (osteocalcin), Alpl (alkaline phosphatase), Spp1 (osteopontin), Ccnd1 (cyclin D1), Actb ( $\beta$-actin), Tnfsf11 (RANKL), Tnfrsf11b (osteoprotegerin), Acp5 (tartrate-resistant acid phosphatase) and Ctsk (cathepsin K). Data represent means \pm S.E.M. from $n=6$ mice per genotype. ${ }^{*} P<0.05$ and $* * P<0.01$ for the comparison between WT and TG mice (by two-sided $t$-test). 
male WT tibiae; Wnt3a and osteocalcin (Bglap) mRNA showed a trend toward increased expression, while osteopontin (Ssp1) and $\beta$-actin (Actb) mRNA were unchanged (Fig. 5F). Expression of the $\beta$-catenin target gene cyclin $\mathrm{D}$ (Ccnd1) was increased $>2$-fold in transgenic bone, and Fra-1 mRNA showed a trend toward increased expression (Fig. 5F), consistent with increased osteoblast proliferation. In contrast, in tibiae isolated from female mice, $\beta$-catenin mRNA was only 1.6-fold higher and the other mRNAs did not differ significantly between WT and transgenic littermates (Supplementary Fig. 5B). Expression of the osteoclast regulators receptor of activated nuclear factor-Kb ligand (RANKL; gene name Tnfsf11) and osteoprotegerin (OPG; Tnfrsf11b), and of two osteoclast-specific genes - tartrate-resistant acid phosphatase (Acp5) and cathepsin $\mathrm{K}($ Ctsk) - were the same in WT and transgenic tibiae of both genders (Fig. 5G and Supplementary Fig. 5C).

\section{Protection from diabetes-induced bone loss in male Col1a1-Prkg2RQ transgenic mice}

We recently demonstrated that the bone loss observed in male mice with type 1 diabetes is at least partly due to impaired NO/cGMP/PKG signaling in osteoblasts, and that restoring cGMP synthesis recovers depressed osteoblast functions in insulin-deficient animals (Kalyanaraman et al. 2018b). We focused on male mice to exclude the influence of estrogens on NO/cGMP signaling. To determine if increased PKG2 activity in osteoblasts is sufficient to protect Col1a1-Prkg2RQ transgenic mice from diabetes-induced bone loss, we induced insulin deficiency by injecting 6 week-old male mice with streptozotocin (STZ). Mice were euthanized six weeks after STZ injections (Fig. 6A). Hyperglycemia was similar in STZ-treated transgenic mice and their WT litter mates (Fig. 6B).

WT mice experienced diabetes-induced bone loss in both trabecular and cortical compartments (Fig. 6C and $\mathrm{D})$, and this was associated with decreased bone formation parameters and decreased expression of osteoblast differentiation- and Wnt-related genes (Fig. 6E and F). Nondiabetic (vehicle-treated) male Col1a1-Prkg $2^{R Q}$ transgenic mice showed higher trabecular and cortical bone volumes compared to their WT litter mates (Fig. 6C and D). The increase in trabecular bone was similar in 8- and 12-weekold mice, but findings in cortical bone were more pronounced at 12 compared to 8 weeks of age (compare Fig. 6C and D to Fig. 4E and Supplementary Fig. 4A). In the transgenic mice, STZ-induced diabetes did not significantly affect trabecular bone and cortical bone area fraction; only cortical thickness and TMD decreased, but most values remained at least as high as those measured in control WT mice (Fig. 6C and D). Similarly, bone formation parameters were elevated in transgenic control mice and remained high after induction of diabetes (Fig. 6E). The protection from bone loss and preservation of bone formation in diabetic Col1a1-Prkg $2^{R Q}$ transgenic mice may relate, at least in part, to increased expression of osteoblast differentiation- and Wnt-related genes (including the $\beta$-catenin target gene cyclin D) (Fig. 6F).

\section{Discussion}

\section{Osteoblast-specific expression of a novel PKG2 mutant at a physiologically-relevant level}

PKG2 deletions in humans and rodents cause dwarfism, and global PKG2 knockout mice exhibit a $\sim 30 \%$ reduction in tibial and femoral length with profound growth plate abnormalities at 8 weeks of age; both genders appear equally affected (Pfeifer et al. 1996, Bonnet et al. 2010, Lipska et al. 2011). Eight week-old Col1a1-Prkg2RQ transgenic mice had normal tibial length and growth plate architecture, consistent with specificity of the $2.3 \mathrm{~kb}$ fragment of the murine Col1a1 promoter for cells of the osteoblastic lineage (Dacquin et al. 2002, Kalajzic et al. 2002). In the mouse embryo, transcription from the $2.3 \mathrm{~kb}$ Col1a1 promoter starts day 14 post conception in ossification centers, where osteoblasts differentiate and initiate bone mineralization (Dacquin et al. 2002). We cannot exclude adaptive developmental changes in the transgenic mice, but the absence of bone deformities and the relatively subtle changes in micro-architecture argue against major developmental changes.

The novel PKG2 $2^{\mathrm{RQ}}$ mutant had modestly increased kinase activity in the absence of cGMP and normal responsiveness to physiological increases in cGMP concentrations. We confirmed tissue-specific expression of the transgene, producing about three-fold increased PKG2 protein and cGMP-stimulated kinase activity in transgenic versus WT POB membranes. Phosphorylation of the PKG substrate VASP was increased in intact transgenic POBs to a degree similar to that seen when osteoblasts are mechanically stimulated or treated with estrogen (Rangaswami et al. 2010, Marathe et al. 2012). Thus, PKG2RQ activity was in a physiologically meaningful range, yet it had profound effects on osteoblast numbers and bone formation parameters. The PKG2 gain of function resulted in cell-autonomous increases in $\mathrm{POB}$ 
A

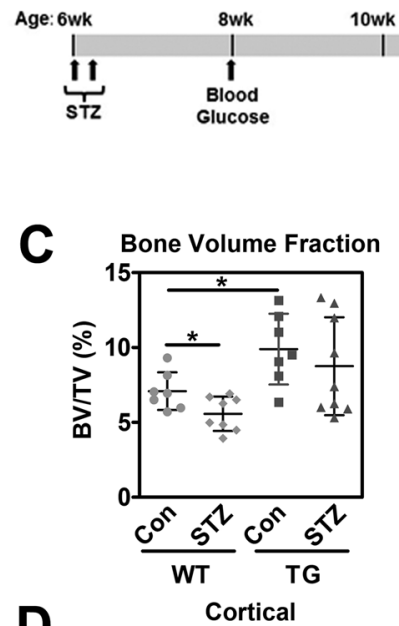

D Bone Area Fraction

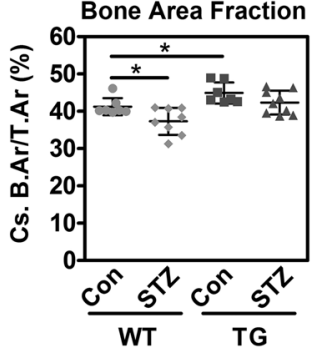

E

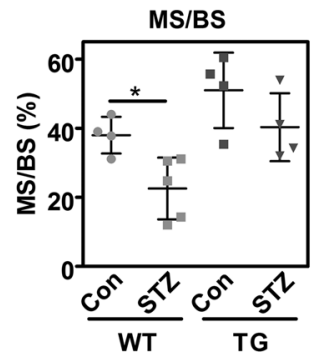

Trabecular Thickness

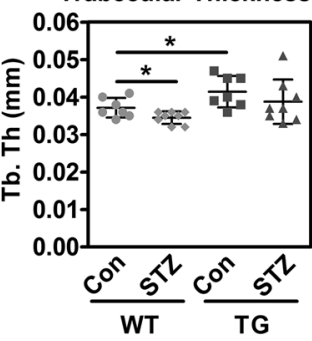

Cortical Thickness

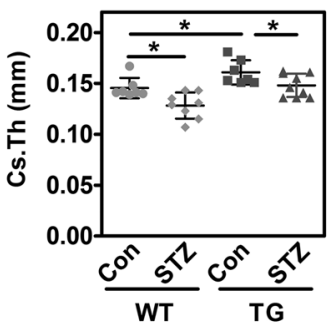

MAR

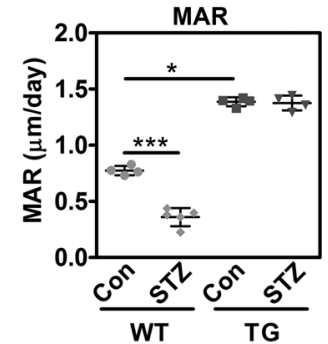

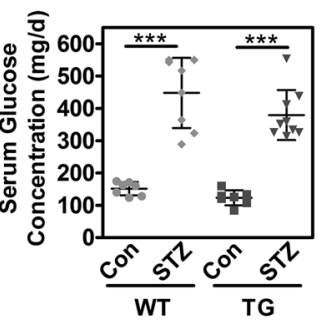

BMD
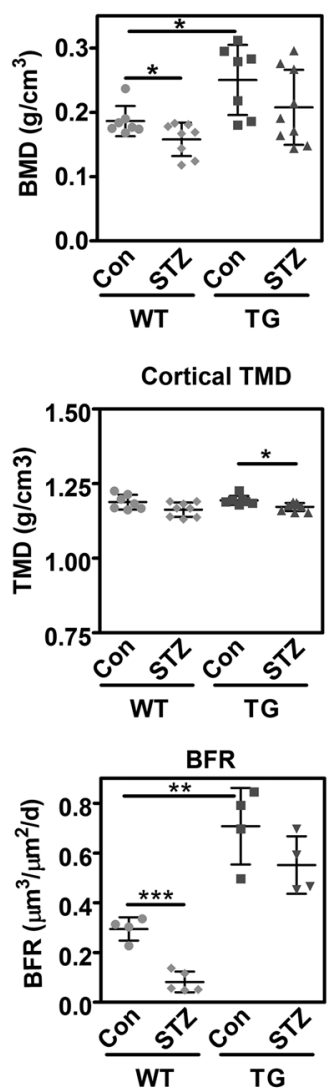
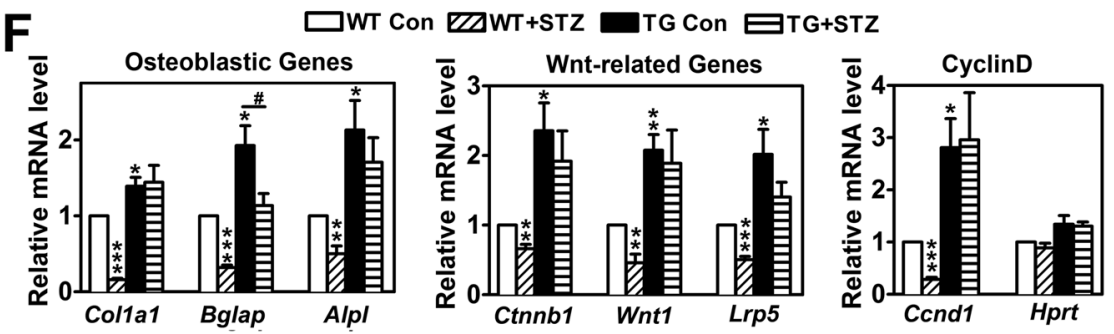

Figure 6

Male Col1a1-Prkg2RQ transgenic mice are protected from diabetes-induced bone loss. (A and B) Six-week-old male mice were injected with vehicle or streptozotocin (STZ, $100 \mathrm{mg} / \mathrm{kg} / \mathrm{d}$ for two days) to induce type 1 diabetes. Blood glucose was measured 12 days later (B), and only hyperglycemic $(>15 \mathrm{mM})$ STZ-treated mice were included in further analyses. All mice received calcein injections 7 and $2 \mathrm{~d}$ prior to euthanasia at the age of 12 weeks. (C and D) Tibiae were analyzed by micro-CT imaging ( $n=7 \mathrm{WT} /$ control, $n=8 \mathrm{WT} / \mathrm{STZ}, n=7 \mathrm{TG} / \mathrm{control}, n=9 \mathrm{TG} / \mathrm{STZ}$ ). Trabecular bone volume fraction, trabecular thickness, and BMD were quantified by micro-CT at the proximal tibia (C). Cortical bone area fraction, cross-sectional thickness, and TMD were quantified at the mid-tibia (D). (E) Endocortical calcein labeling was assessed at the tibia, with quantification of mineralizing surfaces (MS/BS), MAR, and BFR ( $n=4-5$ mice per group). Trabecular calcein labeling in diabetic mice was too weak to allow reliable quantification. Data in dot blots $(\mathrm{B}, \mathrm{C}, \mathrm{D}$ and $\mathrm{E})$ represent means \pm S.D.; ${ }^{*} P<0.05, * * P<0.01, * * * P<0.001$ for the indicated pair-wise comparisons. (F) RNA was extracted from tibial shafts. Relative mRNA abundance of osteoblastic and Wnt-related genes was quantified by qRT-PCR, as was expression of cyclin D (Ccnd1) and Hprt. Gene expression was normalized to $18 \mathrm{~S}$ and data were calculated according to the $\Delta \Delta \mathrm{Ct}$ method, with the mean of the WT control group for each gene assigned a value of one ( $n=6$ mice per group; ${ }^{*} P<0.05, * * P<0.01, * * * P<0.001$ for the comparison to WT control mice, ${ }^{\#} P<0.05$ for the indicated comparison).

\begin{tabular}{|lr}
\hline http://joe.endocrinology-journals.org & ( ) 2018 Society for Endocrinology \\
https://doi.org/10.1530/JOE-18-0286 & Published by Bioscientifica Ltd. \\
Printed in Great Britain
\end{tabular}
Printed in Great Britain 
proliferation and resistance to apoptosis, explaining increased osteoblast numbers and BFR in vivo.

Transgenic mice with chronically elevated plasma CNP concentrations exhibit a prominent skeletal overgrowth phenotype from excess PKG2 activity in growth plate chondroblasts (Miyazawa et al. 2002, Kondo et al. 2015). Since CNP also increases intracellular cGMP concentrations in primary osteoblasts, it is surprising that these mice do not have increased BFRs and show decreased trabecular bone volumes in the femurs of 8 week-old females (data on transgenic males were not reported) (Kondo et al. 2015). Whether CNP stimulates or inhibits osteoblast proliferation is controversial (Hagiwara et al. 1996, Lenz et al. 2010). The reason for these inconsistencies is unclear, but cGMP pools generated by soluble versus receptor GCs may be compartmentalized and differentially activate PKG1 and 2 in different cell types.

\section{Gender-specific differences in the skeletal phenotype of Col1a1-Prkg2RQ transgenic mice}

Male mice expressing the $P r k g 2^{R Q}$ transgene had increased trabecular bone volumes and BMD at two and three months of age, whereas this phenotype was not evident in two month-old female mice. Despite similar PKG2RQ expression in male and female POBs and bones, we found gender-specific differences in nuclear $\beta$-catenin and Wnt/ $\beta$-catenin-related gene expression. The sexual dimorphism of Col1a1-Prkg2RQ transgenic mice likely relates to cross-talk between ER- $\alpha, \mathrm{NO} / \mathrm{cGMP}$ and Wnt/ $\beta$-catenin signaling pathways (Kouzmenko et al. 2004, Mendelsohn $\&$ Karas 2010): First, estrogens increase NO (and cGMP) concentrations in endothelial cells and osteoblasts via ER- $\alpha$ activation of NO synthase (Mendelsohn \& Karas 2010, Marathe et al. 2012, Joshua et al. 2014). Urinary cGMP excretion over $24 \mathrm{~h}$ is higher in pre-menopausal women compared to age-matched men (Markovitz et al. 1997, Cui et al. 2009), but, to our knowledge, there has been no prior direct comparison of serum or tissue NO/cGMP concentrations between males and females. We found higher serum NO and cGMP concentrations in female compared to male mice, consistent with our previous finding that ovariectomy decreases serum cGMP concentration while estrogen supplementation increases it (Joshua et al. 2014). Second, PKG2 directly and indirectly (via Akt) regulates GSK-3 $\beta$ activity, causing $\beta$-catenin stabilization, nuclear translocation, and induction of gene expression (Zhao et al. 2005, Kawasaki et al. 2008, Kalyanaraman et al. 2017).
Female WT POBs produced more NO and cGMP, and had more nuclear $\beta$-catenin compared to male POBs. The higher NO/cGMP activation of endogenous PKG2 may partly obscure the effects of $P K G^{R Q}$ expression in female osteoblasts. Third, PKG2 activation by NO/cGMP increases mRNA and protein expression of the Wnt co-receptor LRP5 (Kalyanaraman et al. 2017). Increased Irp5 expression likely contributed to the increased trabecular bone volume in male Col1a1-Prkg2RQ transgenic mice, because transgenic mice over-expressing WT LRP5 show a similar increase in bone volume (Babij et al. 2003). Multiple reports indicate sexual dimorphism in Wnt/ $\beta$-catenin signaling in bone, possibly caused by direct interactions between $\beta$-catenin and sex hormone receptors (Kouzmenko et al. 2004): (i) the low bone mass phenotype of LRP5 knockout mice and of transgenic mice over-expressing a Wnt inhibitor (secreted frizzledrelated protein-1) is much more severe in males than females (Sawakami et al. 2006, Yao et al. 2010); (ii) the high bone mass phenotype of transgenic mice expressing WT or constitutively-active LRP5 mutants shows genderrelated differences (Babij et al. 2003, Dubrow et al. 2007); and (iii) human studies suggest that associations between genetic LRP5 variants and BMD are stronger in males than in females (Ferrari et al. 2004, Kiel et al. 2007). To fully understand the molecular basis of these genderspecific differences requires further investigation.

\section{Protection from diabetic bone loss by} osteoblast-specific PKG2RQ expression

Low bone turn-over osteoporosis from impaired osteoblastic bone formation is a common complication of type 1 diabetes (Napoli et al. 2016). We have linked defective bone formation to decreased NO/cGMP/PKG signaling in osteoblasts under hyperglycemic conditions and shown that Prkg1 and 2 are both transcriptionally downregulated in bones of insulin-deficient mice (Kalyanaraman et al. 2018b). Here, we provide evidence that increasing PKG2 activity in osteoblasts is sufficient to protect male mice from diabetic bone loss by restoring osteoblast proliferation and activity, in part by preventing downregulation of Wnt/ $\beta$-catenin signaling in diabetic bone. Thus, PKG2 appears to be the major cGMP target in diabetic bone.

\section{Supplementary data}

This is linked to the online version of the paper at https://doi.org/10.1530/ JOE-18-0286. 


\section{Declaration of interest}

The authors declare that they have no conflicts of interest with the contents of this article. The content of the manuscript is solely the responsibility of the authors and does not necessarily represent the official views of the National Institutes of Health.

\section{Funding}

This work was supported by NIH grants R01-AR051300 and R21-AR065658 (to R B P); P01-AG007996 (R L S), P30-CA023100 (UCSD Gene Targeting Mouse Core), P30-NS047101 (UCSD Neuroscience Microscopy Shared Facility) and P30-AR04603 (University of Alabama, Birmingham, Center for Metabolic Bone Disease). N S was supported by the Deutsche Forschungsgemeinschaft (Project KI 1303/2-1).

\section{Authors' contribution statement}

Study design: R B P and G R. Study conduct: G R, N S, H K, N W, J C, D E C, $S \mathrm{M}$, and E C. Data collection: G R, N S, H K, and E C. Data analysis: G R, $H$ K, R L S and R B P. Data interpretation: R B P, G R, H K and R L S. Drafting manuscript: $G R$ and $R B$ P. R B P and $G R$ take responsibility for the integrity of the data analysis.

\section{Acknowledgments}

The authors are grateful to Ella Kothari, Jennifer Santini, Dana Smith and Dezhi Wang for their expert assistance.

\section{References}

Aguirre J, Buttery L, O'Shaughnessy M, Afzal F, de Marticorena IF, Hukkanen M, Huang P, Maclntyre I \& Polak J 2001 Endothelial nitric oxide synthase gene-deficient mice demonstrate marked retardation in postnatal bone formation, reduced bone volume, and defects in osteoblast maturation and activity. American Journal of Pathology 158 247-257. (https://doi.org/10.1016/S0002-9440(10)63963-6)

Armour KE, Armour KJ, Gallagher ME, Godecke A, Helfrich MH, Reid DM \& Ralston SH 2001 Defective bone formation and anabolic response to exogenous estrogen in mice with targeted disruption of endothelial nitric oxide synthase. Endocrinology 142 760-766. (https://doi. org/10.1210/endo.142.2.7977)

Babij P, Zhao W, Small C, Kharode Y, Yaworsky PJ, Bouxsein ML, Reddy PS, Bodine PV, Robinson JA, Bhat B, et al. 2003 High bone mass in mice expressing a mutant LRP5 gene. Journal of Bone and Mineral Research 18 960-974. (https://doi.org/10.1359/jbmr.2003.18.6.960)

Baron R \& Kneissel M 2013 WNT signaling in bone homeostasis and disease: from human mutations to treatments. Nature Medicine 19 179-192. (https://doi.org/10.1038/nm.3074)

Bartels CF, Bukulmez H, Padayatti P, Rhee DK, van Ravenswaaij-Arts C, Pauli RM, Mundlos S, Chitayat D, Shih LY, Al-Gazali LI, et al. 2004 Mutations in the transmembrane natriuretic peptide receptor NPR-B impair skeletal growth and cause acromesomelic dysplasia, type Maroteaux. American Journal of Human Genetics 75 27-34. (https://doi. org/10.1086/422013)

Bocciardi R, Giorda R, Buttgereit J, Gimelli S, Divizia MT, Beri S, Garofalo S, Tavella S, Lerone M, Zuffardi O, et al. 2007 Overexpression of the C-type natriuretic peptide (CNP) is associated with overgrowth and bone anomalies in an individual with balanced $\mathrm{t}(2 ; 7)$ translocation. Human Mutation 28 724-731. (https://doi.org/10.1002/ humu.20511)

Bonnet C, Andrieux J, Beri-Dexheimer M, Leheup B, Boute O, Manouvrier S, Delobel B, Copin H, Receveur A, Mathieu M, et al. 2010 Microdeletion at chromosome 4q21 defines a new emerging syndrome with marked growth restriction, mental retardation and absent or severely delayed speech. Journal of Medical Genetics $\mathbf{4 7}$ 377-384. (https://doi.org/10.1136/jmg.2009.071902)

Bouxsein ML, Boyd SK, Christiansen BA, Guldberg RE, Jepsen KJ \& Muller R 2010 Guidelines for assessment of bone microstructure in rodents using micro-computed tomography. Journal of Bone and Mineral Research 25 1468-1486. (https://doi.org/10.1002/jbmr.141)

Chaudhri RA, Schwartz N, Elbaradie K, Schwartz Z \& Boyan BD 2014 Role of ERa36 in membrane-associated signaling by estrogen. Steroids $\mathbf{8 1}$ 74-80. (https://doi.org/10.1016/j.steroids.2013.10.020)

Chusho H, Tamura N, Ogawa Y, Yasoda A, Suda M, Miyazawa T, Nakamura K, Nakao K, Kurihara T, Komatsu Y, et al. 2001 Dwarfism and early death in mice lacking C-type natriuretic peptide. PNAS $\mathbf{9 8}$ 4016-4021. (https://doi.org/10.1073/pnas.071389098)

Cui R, Iso H, Yamagishi K, Ohira T, Tanigawa T, Kitamura A, Kiyama M, Imano H, Konishi M \& Shimamoto T 2009 Relationship of urinary cGMP excretion with aging and menopausal status in a general population. Journal of Atherosclerosis and Thrombosis 16 457-462. (https://doi.org/10.5551/jat.No083)

Dacquin R, Starbuck M, Schinke T \& Karsenty G 2002 Mouse a1(I)collagen promoter is the best known promoter to drive efficient Cre recombinase expression in osteoblast. Developmental Dynamics 224 245-251. (https://doi.org/10.1002/dvdy.10100)

Dubrow SA, Hruby PM \& Akhter MP 2007 Gender specific LRP5 influences on trabecular bone structure and strength. Journal of Musculoskeletal and Neuronal Interactions 7 166-173.

Ferrari SL, Deutsch S, Choudhury U, Chevalley T, Bonjour JP, Dermitzakis ET, Rizzoli R \& Antonarakis SE 2004 Polymorphisms in the low-density lipoprotein receptor-related protein 5 (LRP5) gene are associated with variation in vertebral bone mass, vertebral bone size, and stature in whites. American Journal of Human Genetics $\mathbf{7 4}$ 866-875. (https://doi.org/10.1086/420771)

Grassi F, Fan X, Rahnert J, Weitzmann MN, Pacifici R, Nanes MS \& Rubin J 2006 Bone re/modeling is more dynamic in the endothelial nitric oxide synthase(-/-) mouse. Endocrinology 147 4392-4399. (https://doi.org/10.1210/en.2006-0334)

Guo DC, Regalado E, Casteel DE, Santos-Cortez RL, Gong L, Kim JJ, Dyack S, Horne SG, Chang G, Jondeau G, et al. 2013 Recurrent gainof-function mutation in PRKG1 causes thoracic aortic aneurysms and acute aortic dissections. American Journal of Human Genetics 93 398-404. (https://doi.org/10.1016/j.ajhg.2013.06.019)

Hagiwara H, Inoue A, Yamaguchi A, Yokose S, Furuya M, Tanaka S \& Hirose S 1996 cGMP produced in response to ANP and CNP regulates proliferation and differentiation of osteoblastic cells. American Journal of Physiology 270 C1311-C1318. (https://doi.org/10.1152/ ajpcell.1996.270.5.C1311)

Hannema SE, van Duyvenvoorde HA, Premsler T, Yang RB, Mueller TD, Gassner B, Oberwinkler H, Roelfsema F, Santen GW, Prickett T, et al. 2013 An activating mutation in the kinase homology domain of the natriuretic peptide receptor-2 causes extremely tall stature without skeletal deformities. Journal of Clinical Endocrinology and Metabolism 98 E1988-E1998. (https://doi.org/10.1210/jc.2013-2358)

Hayashi T, Ito I, Kano H, Endo H \& Iguchi A 2000 Estriol (E3) replacement improves endothelial function and bone mineral density in very elderly women. Journals of Gerontology: Series A, Biological Sciences and Medical Sciences 55 B183-B190. (https://doi.org/10.1093/ gerona/55.4.B183)

Hofmann F, Bernhard D, Lukowski R \& Weinmeister P 2009 cGMP regulated protein kinases (cGK). Handbook of Experimental Pharmacology 191 137-162. (https://doi.org/10.1007/978-3-54068964-5_8) 
Jamal SA, Cummings SR \& Hawker GA 2004 Isosorbide mononitrate increases bone formation and decreases bone resorption in postmenopausal women: a randomized trial. Journal of Bone and Mineral Research 19 1512-1517. (https://doi.org/10.1359/ JBMR.040716)

Joshua J, Schwaerzer GK, Kalyanaraman H, Cory E, Sah RS, Li M, Vaida F, Boss GR \& Pilz RB 2014 Soluble guanylate cyclase as a novel treatment target for osteoporosis. Endocrinology 155 4720-4730. (https://doi. org/10.1210/en.2014-1343)

Kalajzic I, Kalajzic Z, Kaliterna M, Gronowicz G, Clark SH, Lichtler AC \& Rowe D 2002 Use of type I collagen green fluorescent protein transgenes to identify subpopulations of cells at different stages of the osteoblast lineage. Journal of Bone and Mineral Research 17 15-25. (https://doi.org/10.1359/jbmr.2002.17.1.15)

Kalyanaraman H, Schwappacher R, Joshua J, Zhuang S, Scott BT, Klos M, Casteel DE, Frangos JA, Dillmann W, Boss GR, et al. 2014 Nongenomic thyroid hormone signaling occurs through a plasma membrane-localized receptor. Science Signaling 7 ra48. (https://doi. org/10.1126/scisignal.2004911)

Kalyanaraman H, Ramdani G, Joshua J, Schall N, Boss GR, Cory E, Sah RL, Casteel DE \& Pilz RB 2017 A novel, direct NO donor regulates osteoblast and osteoclast functions and increases bone mass in ovariectomized mice. Journal of Bone and Mineral Research 32 46-59. (https://doi.org/10.1002/jbmr.2909)

Kalyanaraman H, Schall N \& Pilz RB $2018 a$ Nitric oxide and cyclic GMP functions in bone. Nitric Oxide 76 62-70. (https://doi.org/10.1016/j. niox.2018.03.007)

Kalyanaraman H, Schwaerzer G, Ramdani G, Castillo F, Scott BT, Dillmann W, Sah RL, Casteel DE \& Pilz RB 2018b Potein kinase G activation reverses oxidative stress and restores osteoblast function and bone formation in male mice with type 1 diabetes. Diabetes $\mathbf{6 7}$ 607-623. (https://doi.org/10.2337/db17-0965)

Kawasaki Y, Kugimiya F, Chikuda H, Kamekura S, Ikeda T, Kawamura N, Saito T, Shinoda Y, Higashikawa A, Yano F, et al. 2008 Phosphorylation of GSK-3beta by cGMP-dependent protein kinase II promotes hypertrophic differentiation of murine chondrocytes. Journal of Clinical Investigation 118 2506-2515. (https://doi.org/10.1172/ JCI35243)

Kiel DP, Ferrari SL, Cupples LA, Karasik D, Manen D, Imamovic A, Herbert AG \& Dupuis J 2007 Genetic variation at the low-density lipoprotein receptor-related protein 5 (LRP5) locus modulates Wnt signaling and the relationship of physical activity with bone mineral density in men. Bone 40 587-596. (https://doi.org/10.1016/j. bone.2006.09.029)

Kondo E, Yasoda A, Fujii T, Nakao K, Yamashita Y, Ueda-Sakane Y, Kanamoto N, Miura M, Arai H, Mukoyama M, et al. 2015 Increased bone turnover and possible accelerated fracture healing in a murine model with an increased circulating C-type natriuretic peptide. Endocrinology 156 2518-2529. (https://doi.org/10.1210/en.2014-1801)

Kouzmenko AP, Takeyama K, Ito S, Furutani T, Sawatsubashi S, Maki A, Suzuki E, Kawasaki Y, Akiyama T, Tabata T, et al. 2004 Wnt/ beta-catenin and estrogen signaling converge in vivo. Journal of Biological Chemistry 279 40255-40258. (https://doi.org/10.1074/jbc. C400331200)

Kuhn M 2016 Molecular physiology of membrane guanylyl cyclase receptors. Physiological Reviews 96 751-804. (https://doi.org/10.1152/ physrev.00022.2015)

Lenz A, Bennett M, Skelton WP \& Vesely DL 2010 Vessel dilator and C-type natriuretic peptide enhance the proliferation of human osteoblasts. Pediatric Research 68 405-408. (https://doi.org/10.1203/ PDR.0b013e3181ef7636)

Lipska BS, Brzeskwiniewicz M, Wierzba J, Morzuchi L, Piotrowski A \& Limon J $20118.6 \mathrm{Mb}$ interstitial deletion of chromosome $4 \mathrm{q} 13.3 \mathrm{q} 21.23$ in a boy with cognitive impairment, short stature, hearing loss, skeletal abnormalities and facial dysmorphism. Genetic Counseling 22 353-363.
Marathe N, Rangaswami H, Zhuang S, Boss GR \& Pilz RB 2012 Prosurvival effects of 17 beta-estradiol on osteocytes are mediated by nitric oxide/cGMP via differential actions of cGMP-dependent protein kinases I and II. Journal of Biological Chemistry 287 978-988. (https:// doi.org/10.1074/jbc.M111.294959)

Markovitz JH, Lewis CE, Sanders PW, Tucker D \& Warnock DG 1997 Relationship of diastolic blood pressure with cyclic GMP excretion among young adults (the CARDIA Study): influence of a family history of hypertension. Coronary Artery Risk Development in Young Adults. Journal of Hypertension 15 955-962. (https://doi. org/10.1097/00004872-199715090-00005)

Mendelsohn ME \& Karas RH 2010 Rapid progress for non-nuclear estrogen receptor signaling. Journal of Clinical Investigation 120 2277-2279. (https://doi.org/10.1172/JCI43756)

Miura K, Namba N, Fujiwara M, Ohata Y, Ishida H, Kitaoka T, Kubota T, Hirai H, Higuchi C, Tsumaki N, et al. 2012 An overgrowth disorder associated with excessive production of cGMP due to a gain-offunction mutation of the natriuretic peptide receptor 2 gene. PLoS ONE 7 e42180. (https://doi.org/10.1371/journal.pone.0042180)

Miyazawa T, Ogawa Y, Chusho H, Yasoda A, Tamura N, Komatsu Y, Pfeifer A, Hofmann F \& Nakao K 2002 Cyclic GMP-dependent protein kinase II plays a critical role in C-type natriuretic peptide-mediated endochondral ossification. Endocrinology 143 3604-3610. (https://doi. org/10.1210/en.2002-220307)

Mueck AO, Seeger H, Ludtke R, Graser T \& Wallwiener D 2001 Effect on biochemical vasoactive markers during postmenopausal hormone replacement therapy: estradiol versus estradiol/dienogest. Maturitas 38 305-313. (https://doi.org/10.1016/S0378-5122(01)00169-4)

Nabhan AF \& Rabie NH 2008 Isosorbide mononitrate versus alendronate for postmenopausal osteoporosis. International Journal of Gynecology and Obstetrics 103 213-216. (https://doi.org/10.1016/j. ijgo.2008.07.011)

Napoli N, Chandran M, Pierroz DD, Abrahamsen B, Schwartz AV \& Ferrari SL 2016 Mechanisms of diabetes mellitus-induced bone fragility. Nature Reviews Endocrinology 13 208-219. (https://doi. org/10.1038/nrendo.2016.153)

Pfeifer A, Aszòdi A, Seidler U, Ruth P, Hofmann F \& Fässler R 1996 Intestinal secretory defects and dwarfism in mice lacking cGMPdependent protein kinase II. Science 274 2082-2086. (https://doi. org/10.1126/science.274.5295.2082)

Rangaswami H, Marathe N, Zhuang S, Chen Y, Yeh JC, Frangos JA, Boss GR \& Pilz RB 2009 Type II cGMP-dependent protein kinase mediates osteoblast mechanotransduction. Journal of Biological Chemistry 284 14796-14808. (https://doi.org/10.1074/jbc. M806486200)

Rangaswami H, Schwappacher R, Marathe N, Zhuang S, Casteel DE, Haas B, Chen Y, Pfeifer A, Kato H, Shattil S, et al. 2010 Cyclic GMP and protein kinase $\mathrm{G}$ control a Src-containing mechanosome in osteoblasts. Science Signaling 3 ra91. (https://doi.org/10.1126/ scisignal.2001423)

Rangaswami H, Schwappacher R, Tran T, Chan GC, Zhuang S, Boss GR \& Pilz RB 2012 Protein kinase $\mathrm{G}$ and focal adhesion kinase converge on Src/Akt/beta-catenin signaling module in osteoblast mechanotransduction. Journal of Biological Chemistry $\mathbf{2 8 7}$ 21509-21519. (https://doi.org/10.1074/jbc.M112.347245)

Rosselli M, Imthurn B, Keller PJ, Jackson EK \& Dubey RK 1995 Circulating nitric oxide (nitrite/nitrate) levels in postmenopausal women substituted with 17 beta-estradiol and norethisterone acetate. A two-year follow-up study. Hypertension 25 848-853. (https://doi. org/10.1161/01.HYP.25.4.848)

Russell KS, Haynes MP, Sinha D, Clerisme E \& Bender JR 2000 Human vascular endothelial cells contain membrane binding sites for estradiol, which mediate rapid intracellular signaling. PNAS 97 5930-5935. (https://doi.org/10.1073/pnas.97.11.5930)

Sawakami K, Robling AG, Ai M, Pitner ND, Liu D, Warden SJ, Li J, Maye P, Rowe DW, Duncan RL, et al. 2006 The Wnt co-receptor 
LRP5 is essential for skeletal mechanotransduction but not for the anabolic bone response to parathyroid hormone treatment. Journal of Biological Chemistry 281 23698-23711. (https://doi.org/10.1074/jbc. M601000200)

Vaandrager AB, Ehlert EME, Jarchau T, Lohmann SM \& De Jonge HR 1996 $\mathrm{N}$-terminal myristoylation is required for membrane localization of cGMP-dependent protein kinase type II. Journal of Biological Chemistry 271 7025-7029. (https://doi.org/10.1074/jbc.271.12.7025)

Vaandrager AB, Hogema BM \& De Jonge HR 2005 Molecular properties and biological functions of cGMP-dependent protein kinase II. Frontiers in Bioscience 10 2150-2164. (https://doi.org/10.2741/1687)

van't Hof RJ \& Ralston SH 2001 Nitric oxide and bone. Immunology 103 255-261. (https://doi.org/10.1046/j.1365-2567.2001.01261.x)

Watanuki M, Sakai A, Sakata T, Tsurukami H, Miwa M, Uchida Y, Watanabe K, Ikeda K \& Nakamura T 2002 Role of inducible nitric oxide synthase in skeletal adaptation to acute increases in mechanical loading. Journal of Bone and Mineral Research 17 1015-1025. (https:// doi.org/10.1359/jbmr.2002.17.6.1015)

Wimalawansa SJ 2000 Nitroglycerin therapy is as efficacious as standard estrogen replacement therapy (Premarin) in prevention of oophorectomy-induced bone loss: a human pilot clinical study. Journal of Bone and Mineral Research 15 2240-2244. (https://doi. org/10.1359/jbmr.2000.15.11.2240)

Wimalawansa SJ 2007 Rationale for using nitric oxide donor therapy for prevention of bone loss and treatment of osteoporosis in humans. Annals of the New York Academy of Sciences 1117 283-297. (https://doi. org/10.1196/annals.1402.066)

Wimalawansa SJ, De MG, Gangula P \& Yallampalli C 1996 Nitric oxide donor alleviates ovariectomy-induced bone loss. Bone 18 301-304. (https://doi.org/10.1016/8756-3282(96)00005-1)

Yao W, Cheng Z, Shahnazari M, Dai W, Johnson ML \& Lane NE 2010 Overexpression of secreted frizzled-related protein 1 inhibits bone formation and attenuates PTH bone anabolic effects. Journal of Bone and Mineral Research 25 190-199. (https://doi.org/10.1359/ jbmr.090719)

Zhao X, Zhuang S, Chen Y, Boss GR \& Pilz RB 2005 Cyclic GMPdependent protein kinase regulates CCAAT enhancer-binding protein beta functions through inhibition of glycogen synthase kinase-3. Journal of Biological Chemistry 280 32683-32692. (https://doi. org/10.1074/jbc.M505486200)

Received in final form 8 June 2018

Accepted 18 June 2018

Accepted Preprint published online 18 June 2018
() 2018 Society for Endocrinology Published by Bioscientifica Ltd. Printed in Great Britain 